NBER WORKING PAPER SERIES

\title{
ESTIMATING PRODUCTION FUNCTIONS IN DIFFERENTIATED-PRODUCT INDUSTRIES WITH QUANTITY INFORMATION AND EXTERNAL INSTRUMENTS
}

\author{
Nicolás de Roux \\ Marcela Eslava \\ Santiago Franco \\ Eric Verhoogen \\ Working Paper 28323 \\ http://www.nber.org/papers/w28323
NATIONAL BUREAU OF ECONOMIC RESEARCH
1050 Massachusetts Avenue
Cambridge, MA 02138
January 2021

We would like to thank Mons Chan, Rafael Dix-Carneiro, Dave Donaldson, Garth Frazer, Pete Klenow, Sebastian Kripfganz, Jeanne LaFortune, Suresh Naidu, José Tessada, Reed Walker, Frederic Warzynski, and participants in several seminars for helpful comments, and Nathalie González and Cristhian Acosta for excellent research assistance. We are grateful to DANE staff for facilitating data access and for advice on the proper use of the data. The views expressed in this document are not those of DANE or DANE staff. All analysis using confidential data was carried out in accordance with Colombian confidentiality laws. All errors are our own. The views expressed herein are those of the authors and do not necessarily reflect the views of the National Bureau of Economic Research.

NBER working papers are circulated for discussion and comment purposes. They have not been peer-reviewed or been subject to the review by the NBER Board of Directors that accompanies official NBER publications.

(C) 2021 by Nicolás de Roux, Marcela Eslava, Santiago Franco, and Eric Verhoogen. All rights reserved. Short sections of text, not to exceed two paragraphs, may be quoted without explicit permission provided that full credit, including $\odot$ notice, is given to the source. 
Estimating Production Functions in Differentiated-Product Industries with Quantity Information and External Instruments

Nicolás de Roux, Marcela Eslava, Santiago Franco, and Eric Verhoogen

NBER Working Paper No. 28323

January 2021

JEL No. D24,L1,L65,O14

\begin{abstract}
$\underline{\text { ABSTRACT }}$
This paper develops a new method for estimating production-function parameters that can be applied in differentiated-product industries with endogenous quality and variety choice. We take advantage of data on physical quantities of outputs and inputs from the Colombian manufacturing survey, focusing on producers of rubber and plastic products. Assuming constant elasticities of substitution of outputs and inputs within firms, we aggregate from the firm-product to the firm level and show how quality and variety choices may bias standard estimators. Using real exchange rates and variation in the "bite" of the national minimum wage, we construct external instruments for materials and labor choices. We implement a simple two-step instrumentalvariables method, first estimating a difference equation to recover the materials and labor coefficients and then estimating a levels equation to recover the capital coefficient. Under the assumption that the instruments are uncorrelated with firms' quality and variety choices, this method yields consistent estimates, free of the quality and variety biases we have identified. Our point estimates differ from those of existing methods and changes in our preferred productivity estimator perform relatively well in predicting future export growth.
\end{abstract}

Nicolás de Roux

Department of Economics

Universidad de los Andes

Calle 19A No 1-37 Este, W 823

Bogotá, Colombia

nicolas.de.roux@uniandes.edu.co

Marcela Eslava

Department of Economics

Universidad de los Andes

Calle 19A \# 1-37 Este. Bloque W of. 810

Bogotá, Colombia

meslava@uniandes.edu.co
Santiago Franco

Kenneth C. Griffin Department of Economics

University of Chicago

1126 E. 59th St.

Chicago, IL 60637

sfranco@uchicago.edu

Eric Verhoogen

Department of Economics

School of International \& Public Affairs

Columbia University

420 W. 118th Street

New York, NY 10027

and IZA

and also NBER

eric.verhoogen@columbia.edu

A data appendix is available at http://www.nber.org/data-appendix/w28323 


\section{Introduction}

A central challenge in estimating production functions is to estimate the elasticities of real output with respect to real inputs, unconfounded by differences in prices across firms. Estimates of these elasticities are key to constructing standard measures of total factor productivity (TFP), the most commonly used metric of firm performance. They are also important for estimating markups in the influential method of Hall (1986) and De Loecker and Warzynski (2012). As recently emphasized by Bond et al. (2020), that method requires an elasticity of real output, not of sales or value-added, in order to generate informative estimates of markups.

Two difficulties in estimating such elasticities have received particular attention. First, prices and physical quantities of outputs and inputs are usually not observed at the firm (or plant) level. The most common solution is to regress sales (or value-added), deflated by a sector-level price index, on material expenditures and other inputs, similarly deflated. It has long been recognized that the resulting estimates may reflect idiosyncratic variation in market power at the firm level (Klette and Griliches, 1996; Foster et al., 2008, 2016; De Loecker and Goldberg, 2014). Second, firms may choose variable inputs after observing shocks to their own productivity in a given period, generating a positive correlation between unobserved productivity shocks and the input choices — the familiar "transmission bias" problem, first noted by Marschak and Andrews (1944). ${ }^{1}$

Information on prices and quantities at the firm-product level, while still uncommon, is increasingly available and has enabled researchers to make progress on the first issue. Focusing on eleven homogeneous products in the US Census of Manufactures, Foster et al. (2008) estimate regressions with physical output quantities on the left-hand side, yielding output elasticities arguably purged of demand-side influences. Although Foster et al. (2008) do not use physical quantities of inputs, in cases where inputs are homogeneous and quantities are observed it is straightforward to extend their approach and put physical quantities of inputs on the right-hand side (Atalay, 2014).

But as suggested by Katayama et al. (2009), Grieco and McDevitt (2016), Atkin et al. (2019), Jaumandreu and Yin (2018) and others, using physical quantities may be misleading in differentiated-product industries where the quality and variety of outputs and inputs vary across firms and over time. If consumers value product quality and variety, then they should be

\footnotetext{
${ }^{1}$ For reviews, see Griliches and Mairesse (1998), Bartelsman and Doms (2000), Ackerberg et al. (2007), Van Biesebroeck (2008), Syverson (2011), De Loecker and Goldberg (2014), Section 2 of Ackerberg et al. (2015), and Section 2.2.1 of Verhoogen (2020).
} 
incorporated in our notion of real output; similarly, if input quality and variety matter for real output, then they should be incorporated in real inputs. But once one accepts these propositions, estimates using only physical units may be subject to what we call quality and variety biases. For instance, a firm may take advantage of an increase in capability to produce fewer physical units of higher-quality goods (for a given set of inputs), generating a negative bias in output elasticities estimated using only physical output quantities. If more-productive firms tend to use higher-quality inputs and this choice is correlated with the physical quantity of inputs used, then another form of bias arises, with the direction depending on the sign of the input quality-quantity correlation. Similar biases can also result from the endogenous choice of variety by firms, or from exogenous shocks to product appeal or input quality, if firms' choices of physical units of inputs respond.

In this paper, we develop a new approach to estimating output elasticities that takes advantage of quantity information, that is arguably not subject to quality or variety biases, and that also addresses the transmission-bias problem. The method can be applied in horizontally and vertically differentiated industries with multi-product firms and requires relatively weak theoretical assumptions on the nature of demand and market competition. We implement it in data from the Colombian manufacturing survey, which contains information on prices and quantities of both inputs and outputs, focusing (for reasons discussed below) on producers of rubber and plastic products.

The paper makes three main contributions. The first is to highlight conceptually how estimates of output elasticities based on physical quantities may be misleading in industries where quality and variety vary differentially by firm over time. As in almost all similar datasets, the mapping between specific inputs and specific outputs within the firm is unobserved. ${ }^{2}$ Our approach is to aggregate from the firm-product to the firm level. It is not possible to do this aggregation in a theory-free way; any aggregation embeds assumptions, implicit or explicit, about consumer and firm behavior. Here we assume that outputs and inputs, respectively, have constant elasticities of substitution (CES) within firms. We place minimal constraints on substitution elasticities across firms. Following common practice, we assume that (firm-level aggregate) materials, labor, and capital combine in Cobb-Douglas fashion. Although restrictive, the within-firm CES structure is convenient in that it allows us to express the change in each aggregate as the sum of an observ-

\footnotetext{
${ }^{2}$ We are aware of only two exceptions with a substantial number of firms, a dataset on Bangladeshi garment firms used by Cajal Grossi et al. (2019) and one on Chinese steel firms used by Brandt et al. (2018).
} 
able quantity index and unobservable terms capturing quality and variety. This in turn makes transparent how differences in quality and variety may bias standard estimates. Empirically, we will show that our estimates are robust to using other common aggregators at the firm level.

Our second contribution is to address transmission bias by introducing "external" instruments capturing exogenous variation in input prices at the firm level. The idea that external instruments in general, and input prices in particular, would be an attractive solution to the transmission-bias problem has been "in the air" for many years, at least since the landmark review by Griliches and Mairesse (1998). ${ }^{3}$ Several recent papers have acknowledged that factor prices would be natural instruments, but have argued that it would be difficult to find truly exogenous variation at the firm level. ${ }^{4}$ In the absence of credible external instruments, two approaches have dominated the recent literature. One has been to construct a proxy for unobserved productivity by inverting either an investment-demand or a materials-demand equation, which requires a monotonic relationship between the productivity term (assumed to be scalar) and investment or materials, conditional on other observables (Olley and Pakes, 1996; Levinsohn and Petrin, 2003; Wooldridge, 2009; De Loecker, 2011; Doraszelski and Jaumandreu, 2013, 2018; Ackerberg et al., 2015; Gandhi et al., 2020). Another approach has been to construct "internal" instruments using lagged values of inputs (Chamberlain, 1982; Anderson and Hsiao, 1982; Arellano and Bond, 1991; Arellano and Bover, 1995; Blundell and Bond, 1998, 2000). ${ }^{5}$ In this panel-data approach, the most successful strategy has been the "System GMM" estimator of Arellano and Bover (1995) and Blundell and Bond (1998, 2000), which supplements an equation in first differences, using lagged levels as instruments, with an equation in levels, using lagged differences as instruments.

Our aggregation strategy requires firm-specific normalizations, which we absorb with a firm effect in our main estimating equation. As a consequence, the proxy-variable strategy is not an attractive option, because the firm effect would violate the required monotonicity assumption

\footnotetext{
${ }^{3}$ Griliches and Mairesse (1998) write that the "future" of production-function estimation lies in "find[ing] (instrumental) variables that have genuine information about factors which affect firms differentially as they choose their input levels" (p. 198) and describe using "factor prices ... as instrumental variables to identify the parameters of interest" as an "obvious" solution. Nerlove (1963) is an early paper using an external instrument — electricity prices - in production-function estimation.

${ }^{4}$ For instance, Ackerberg et al. (2015, p, 2418, fn 3) write: "if one observed exogenous, across-firm-variation in all input prices, estimating the production function using input price based IV methods might be preferred to OP/LP [Olley-Pakes/Levinsohn-Petrin] related methodology (due to fewer auxiliary assumptions)." But they also note that "the premise of most of this [proxy-variable] literature is that such variables are either not available or not believed to be exogenous." See also Ackerberg et al. (2007, p. 4208) and Gandhi et al. (2020, Sec. 6.1).

${ }^{5}$ The two dominant approaches are themselves related, since the proxy-variable methods often use lagged levels as instruments, as discussed in Ackerberg et al. (2015, Sec. 4.3.3).
} 
(Ackerberg et al., 2015). We instead build on the panel-data approach, which more easily accommodates the firm effect. But rather than include further and further lags as instruments, which is commonly done but may raise concerns about instrument strength, we include a parsimonious set of lags and two external instruments capturing exogenous variation in input prices. To construct the materials-price instrument, we first use exchange rates to predict import-price changes at the product level, omitting one firm at a time in making the predictions. We then use the lagged product composition of a firm's imports, in conjunction with the "leave one out" predicted import-price changes, to construct a firm-specific predicted import price index. To construct the wage instrument, we interact changes in the national minimum wage, which saw large increases in real terms over our study period, with an indicator for how binding the change was likely to be on particular firms (the "bite" of the minimum wage), defined as the lagged ratio of the minimum wage to the average wage for permanent employees in the firm. We will see that the external instruments are helpful in alleviating (if not completely removing) weak-instrument concerns.

In estimating the coefficient on capital, we face a well-known difficulty: methods with transformations to remove firm effects — either first-differencing or deviating from firm means — tend to yield implausibly low estimates. ${ }^{6}$ The most common explanation is that transformations to remove the firm effect exacerbate the attenuation bias due to measurement error; other explanations, discussed below, are also possible (Griliches and Mairesse, 1998). Others have found that this problem persists when instrumenting the change in capital with lagged levels (see e.g. Ornaghi (2006)). Fundamentally, the issue is that much of the genuine variation in capital stock is cross-sectional; the within-firm evolution of capital stock - and, in particular, of utilized capital - is very difficult to measure well. The main existing approaches, proxy-variable methods and System GMM, both rely to some extent on cross-sectional variation to estimate the capital coefficient.

Our third contribution is an approach to estimation that allows us both to absorb the firm effect when estimating the materials and labor coefficients and to take advantage of cross-sectional variation to estimate the capital coefficient. In the broad spirit of System GMM, we combine a difference equation, using lagged levels as instruments, with a levels equation, using lagged differences as instruments. But rather than estimating the equations simultaneously using GMM, we estimate them separately in what we call a two-step instrumental-variables (TSIV) procedure.

\footnotetext{
${ }^{6}$ See e.g. Griliches and Mairesse (1998), Ackerberg et al. (2007), and Ackerberg et al. (2015).
} 
In the first step, we first-difference and use the external instruments described above, together with a parsimonious set of lagged levels, to recover the coefficients on materials and labor. In the second step, we use the first-step estimates of the materials and labor coefficients and impose an additional assumption that ensures orthogonality between the lagged difference in log capital and the firm effect; this allows us to use the lagged difference of capital as an instrument in an IV model in levels. ${ }^{7}$ If the model is correctly specified, the TSIV estimator is less efficient than simultaneous GMM estimation of the difference and levels equations, but it has the advantage that the materials and labor coefficient estimates are robust to misspecification of the levels equation (Kripfganz and Schwarz, 2019).

The TSIV procedure yields plausible point estimates: we find materials and labor coefficients of approximately .4, and a capital coefficient of approximately .2. The fact that constant returns to scale approximately hold is reassuring. Although the standard errors are large enough that the differences with standard estimators are generally not statistically significant, the point estimates display some interesting patterns. The materials coefficient is lower than, and the labor coefficient larger than, the coefficients from (a) naive OLS estimation using revenues for output and materials expenditures for material input, (b) the Olley and Pakes (1996) and Levinsohn and Petrin (2003) proxy-variable methods, and (c) standard System GMM. ${ }^{8}$ Somewhat surprisingly, our estimates (including for capital) are similar to those from OLS in levels using our constructed quantity aggregates.

The main goal of this paper is to provide a new approach to estimating output elasticities, which are useful for several purposes, including calculating markups. But it is natural to ask how TFP measures constructed from our estimates perform relative to other TFP measures commonly used in the literature. We face a choice between a revenue-based TFP and a quantity-based TFP measure based on our quantity indexes. We note that even with our improved estimates of output elasticities, neither measure corresponds directly to technical efficiency. Our revenue-based TFP may reflect pure output or input price differences, and our quantity-based TFP may be biased by quality and variety choices (even if the output-elasticity estimates are not). We favor using revenue-based TFP, and keeping in mind that it may capture price differences as well as technical efficiency. To compare with TFP estimates from other methods, we examine the extent to which

\footnotetext{
${ }^{7}$ The second-step approach is akin to that of Collard-Wexler and De Loecker (2016).

${ }^{8}$ Our materials estimate is quite similar to the one we obtain by applying Gandhi et al. (2020) in our data, and our labor coefficient is somewhat smaller.
} 
estimated changes in revenue-based TFP predict future changes in export performance, and we find that our estimates compare well to standard methods.

In addition to the studies cited above, this paper is related to several branches of literature. It is perhaps most closely related to a small number of studies on production-function estimation in multi-product firms using information at the firm-product level. This literature has dealt in different ways with the lack of an observed mapping between inputs and outputs in multi-product firms. One strategy has been to focus on single-product firms, for which the mapping is clear, and (in some cases) to do a selection correction for the fact that they may not be representative (Foster et al., 2008; De Loecker et al., 2016; Garcia-Marin and Voigtländer, 2019; Balat et al., 2018; Blum et al., 2018). ${ }^{9}$ Recent work by Dhyne et al. (2020a,b) develops an alternative strategy of estimating simultaneous equations relating output of each good to firm-level input usage and the output levels of other goods. This strategy requires as many proxies as products and a multidimensional generalization of the monotonicity condition, and it tends to reject the hypothesis that single-product production is a good approximation for multi-product production. Another approach has been to use estimates of demand elasticities and profit-maximization conditions to infer the allocation of inputs to outputs that would be implemented by optimizing firms (Orr, 2020; Valmari, 2016). ${ }^{10}$ Our strategy, by contrast, is to aggregate both outputs and inputs to the firm level. Previous papers that have aggregated from the firm-product to the firm level include Eslava et al. (2004, 2013), Ornaghi (2006), Doraszelski and Jaumandreu (2013), Smeets and Warzynski (2013) and Bas and Paunov (2020). ${ }^{11}$ These papers do not use CES aggregators, nor do they show how explicitly how quality or variety differences enter firm-level price or quantity indexes. Our approach builds on an extensive literature using CES functions in addressing other questions, including Feenstra (1994), Hsieh and Klenow (2009), Hottman et al. (2016), and Redding and Weinstein (2020).

This paper is also related to studies that explicitly consider differences in the quality of outputs or inputs in a production-function context. Melitz (2000), Katayama et al. (2009), and Grieco et

\footnotetext{
${ }^{9}$ Foster et al. (2008) include in their sample only firms in which one product makes up more than $50 \%$ of revenues, thus essentially focusing on single-product firms. De Loecker et al. (2016) implement a modified version of the Ackerberg et al. (2015) proxy-variable method and focus on calculating mark-ups at the firm-product level in Indian data. In Chilean data, Garcia-Marin and Voigtländer (2019) use firm-product-level markups calculated along the same lines to infer marginal costs and to relate them to firms' export behavior.

${ }^{10}$ See also Gong and Sickles (2019) and Forlani et al. (2016).

${ }^{11}$ Dhyne et al. (2020a) and Garcia-Marin and Voigtländer (2019) employ similar aggregations in parts of their analyses.
} 
al. (2016) propose estimators that take quality differences into account in settings where productlevel information is not observed; the lack of direct price and quantity data means that they must rely on more restrictive theoretical assumptions than we do here. Fox and Smeets (2011) show that including detailed indicators of labor quality significantly reduces the dispersion of estimated productivities across firms in Denmark, but they do not have product-level information on outputs or inputs. For the most part, the literature exploiting information at the firm-product level does not explicitly take into account quality or variety differences. Exceptions include De Loecker et al. (2016) and Eslava and Haltiwanger (2020), who use control-function approaches to address potential quality and variety biases. ${ }^{12}$ Two recent papers take advantage of detailed product characteristics in particular sectors. Focusing on outpatient dialysis centers in the US, Grieco and McDevitt (2016) find that firms trade off quality and quantity of care, suggesting that measures of performance based solely on quantity can be misleading. In an Egyptian rug cluster, Atkin et al. (2019) collect direct measures of rug quality and producer performance under laboratory conditions and also find that purely quantity-based measures of performance are misleading. Such direct measures of product quality are clearly very valuable for estimating firm performance, but unfortunately they are rarely available. We view our method as being most useful in settings where product prices and quantities are available but detailed product characteristics are not.

Relative to the existing literature, our approach has costs and benefits. On one hand, some of our assumptions are stronger than those of other methods. We impose an unusually strong (but testable) restriction on the evolution of unobserved productivity, discussed below. We require exclusion restrictions for our instruments. We do not consider firms' endogenous investments in raising productivity, as do for instance Doraszelski and Jaumandreu (2013, 2018). The withinfirm CES assumptions are restrictive (although the empirical patterns are robust to using other aggregators). On the other hand, we are able to avoid some strong assumptions required by other methods. We do not need a scalar monotonicity condition to ensure invertibility of an investment or materials-demand function as in proxy-variable methods. Although we presume some maxi-

\footnotetext{
${ }^{12}$ De Loecker et al. (2016) describe their approach as addressing "input price bias" and "output price bias" and do not explicitly address what we call quality and variety biases. They put flexible functions of output prices and market shares in a control function for input demand and put physical quantities of output on the left-hand side. Arguably, this approach completely removes quality biases only in the special case where input and output quality are perfectly correlated, which is unlikely to hold exactly in practice, and does not address what we call variety biases. Eslava and Haltiwanger (2020) also use CES aggregation, but they do so in the context of joint GMM estimation of production and demand functions, which requires CES across as well as within firms, while here we do not need to impose a particular demand structure across firms.
} 
mizing behavior on the part of firms to justify the CES aggregation, we do not need first-order conditions for aggregate materials or labor to hold exactly as in Doraszelski and Jaumandreu (2013, 2018) and Gandhi et al. (2020). We can remain agnostic about cross-firm demand elasticities. Relative to the panel-data literature, we are able to reduce the reliance on lagged internal instruments. We can also relax the assumptions required for the levels equation in System GMM, and do not need them at all if we are only interested in the output elasticities with respect to materials and labor. We explicitly consider output and input quality and variety differences, as relatively few other papers have done. While there are trade-offs, we believe that, on balance, our method represents an attractive alternative to existing methods in differentiated-product industries where quantity information and external instruments are available.

The next section develops our econometric strategy. Section 3 describes the data we use and our motivation for focusing on producers of rubber and plastic products. Section 4 presents our baseline estimates of output elasticities, and Section 5 conducts several robustness checks. Section 6 compares our coefficient estimates to those of other common estimation methods. Section 7 constructs productivity measures using our coefficient estimates and examines how well they do, relative to existing measures, in predicting future export performance. Section 8 concludes.

\section{Econometric Strategy}

This section first presents the theoretical framework that underpins our firm-level aggregation and estimating equations. We begin on the demand side (Subsection 2.1) and then turn to the production side (Subsection 2.2) and rewrite the production function using decompositions of our output and input aggregates, which makes clear how endogenous quality and variety choices may bias standard estimates (Subsection 2.3). We then present our two-step IV (TSIV) strategy (Subsection 2.4). Full derivations are in Appendix A.

\subsection{Demand}

The first task is to construct a measure of real output at the firm level - firm-level sales deflated by an appropriate firm-specific price index. In differentiated-good industries, any price index necessarily embeds assumptions about how a firm's products enter consumers' utility. Here we follow Hottman et al. (2016) and others in imposing constant elasticity of substitution of products 
within firms. This is restrictive, but unlike much of the existing literature we do not need to make strong assumptions about the elasticity of substitution of products across firms. (We will also show (in Section 5.1 below) that the empirical patterns are robust to using other common aggregators.)

We assume that a representative consumer has the following utility function:

$$
U_{t}=U\left(\widetilde{Y}_{1 t}, \widetilde{Y}_{2 t}, \ldots, \widetilde{Y}_{I t}\right) \text { where } \widetilde{Y}_{i t}=\left[\sum_{j \in \Omega_{i t}^{y}}\left(\varphi_{i j t} Y_{i j t}\right)^{\frac{\sigma_{i}^{y}-1}{\sigma_{i}^{y}}}\right]^{\frac{\sigma_{i}^{y}}{\sigma_{i}^{y}-1}}
$$

Here $i, j$ and $t$ index firms, products (outputs), and periods (years), $I$ is the total number of firms, $Y_{i j t}$ is physical quantity of output, $\sigma_{i}^{y}$ is the elasticity of substitution between outputs, specific to firm $i$, and $\Omega_{i t}^{y}$ is the set of products sold by the firm. The $\varphi_{i j t}$ terms are demand shifters that can be interpreted as product appeal or quality, which may reflect endogenous choices of the firm (e.g. physical attributes of goods) or external factors (e.g. exogenous fashion trends). We assume that $U(\cdot)$ is quasi-concave and weakly separable in its arguments. We follow common practice and assume that $\sigma_{i}^{y}>1$. Although the consumer optimization problem would remain well-behaved as long as $\sigma_{i}^{y}>0,{ }^{13}$ the stronger $\sigma_{i}^{y}>1$ ensures that the representative consumer will purchase more units of a good that increases in appeal, which seems realistic in our context. ${ }^{14}$

The assumption of weak separability and the homotheticity of $\widetilde{Y}_{i t}$ imply that the consumer's optimization problem can be solved in two stages, first choosing the quantity of each variety from firm $i, Y_{i j t}$, to minimize the cost of acquiring each unit of $\widetilde{Y}_{i t}$ and second choosing $\widetilde{Y}_{i t}$ to maximize utility. Assuming the consumer optimizes in the first stage, the price required to purchase one unit of $\widetilde{Y}_{i t}$ is:

$$
\widetilde{P}_{i t}=\left[\sum_{j \in \Omega_{i t}^{y}}\left(\frac{P_{i j t}}{\varphi_{i j t}}\right)^{1-\sigma_{i}^{y}}\right]^{\frac{1}{1-\sigma_{i}^{y}}}
$$

This is the price index that sets $\widetilde{P}_{i t} \widetilde{Y}_{i t}=R_{i t}$, where $R_{i t}$ is the consumer's total expenditures on goods of firm $i$, which are also the firm's revenues. Note that it is quality-adjusted: conditional

\footnotetext{
${ }^{13}$ See Appendix A.1. For the knife-edge Cobb-Douglas case of $\sigma_{i}^{y}=1$, we would need an additional condition to ensure that the optimization problem remains well-behaved.

${ }^{14}$ As noted by Redding and Weinstein (2020), $\sigma_{i}^{y}>1$ is sufficient to ensure that products are "connected substitutes" in the sense of Berry et al. (2013) and hence that the demand system is invertible. This is a sufficient condition, not a necessary one, and our method could be implemented in settings with a greater degree of complementarity between products, but for reasons of realism and convenience we maintain the standard assumption.
} 
on the price of a given output, higher output quality reduces the value of the index.

An attractive feature of our approach is that we do not need to impose further assumptions on demand. The assumption of quasi-concavity implies that there is a unique demanded bundle, given by:

$$
\widetilde{Y}_{i t}=D_{i t}\left(\widetilde{P}_{1 t}, \ldots, \widetilde{P}_{I t}, C_{t}\right) \text { for } i=1,2, \ldots, I
$$

where $C_{t}$ is total consumption in period $t$. The demand for the output aggregate of a given firm depends only on the firm's own aggregate price index, the price indexes of other firms, and total consumption. We can leave the $D(\cdot)$ function unspecified.

The within-firm CES assumption allows us to decompose changes in the firm-specific price index in a particularly convenient way. Let $\Omega_{i t}^{y *}$ be firm $i$ 's common outputs between $t-1$ and $t$ (i.e. $\Omega_{i t-1}^{y} \cap \Omega_{i t}^{y}$ ), $R_{i t}^{*}$ be the consumer's expenditures on common goods (i.e. common-goods revenue for the firm), $\widetilde{P}_{i t}^{*}$ and $\widetilde{Y}_{i t}^{*}$ be the price and quantity indexes for common goods analogous to $\widetilde{P}_{i t}$ and $\widetilde{Y}_{i t}, S_{i j t}^{y}$ be the consumer's expenditure share on product $j$ among all products produced by firm $i$, and $S_{i j t}^{y *}$ be the corresponding share among common goods. ${ }^{15}$ Following Sato (1976), Vartia (1976), Feenstra (1994) and Redding and Weinstein (2020), it is straightforward to show (see Appendix A.1) that the log change in the firm-specific price level can be expressed as:

$$
\ln \left(\frac{\widetilde{P}_{i t}}{\widetilde{P}_{i t-1}}\right)=\underbrace{\sum_{j \in \Omega_{i t}^{y *}} \delta_{i j t} \ln \left(\frac{P_{i j t}}{P_{i j t-1}}\right)-\sum_{j \in \Omega_{i t}^{y *}} \delta_{i j t} \ln \left(\frac{\varphi_{i j t}}{\varphi_{i j t-1}}\right)}_{=\ln \left(\frac{\widetilde{P}_{i t}^{*}}{\widetilde{P}_{i t-1}^{*}}\right)}-\frac{1}{\sigma_{i}^{y}-1} \ln \left(\frac{\chi_{i t-1, t}^{y}}{\chi_{i t, t-1}^{y}}\right)
$$

where:

$$
\delta_{i j t}=\frac{\left(\frac{S_{i j t}^{y *}-S_{i j t-1}^{y *}}{\ln S_{i j t}^{y *}-\ln S_{i j t-1}^{y *}}\right)}{\sum_{j \in \Omega_{i t}^{y *}}\left(\frac{S_{i j t}^{y *}-S_{i j t-1}^{y *}}{\ln S_{i j t}^{y *}-\ln S_{i j t-1}^{y *}}\right)}, \quad \chi_{i t, t-1}^{y}=\sum_{j \in \Omega_{i t}^{y *}} S_{i j t}^{y}, \quad \chi_{i t-1, t}^{y}=\sum_{j \in \Omega_{i t}^{y *}} S_{i j t-1}^{y}
$$

The first term on the right-hand side of (4) is (the log of) the familiar Sato-Vartia index (Sato, 1976; Vartia, 1976); it is an observable weighted average of product-specific price changes for

\footnotetext{
${ }^{15}$ That is, $R_{i t}^{*}=\sum_{\Omega_{i t}^{y *}} P_{i j t} Y_{i j t}, \widetilde{P}_{i t}^{*}=\left[\sum_{j \in \Omega_{i t}^{y *}}\left(P_{i j t} / \varphi_{i j t}\right)^{1-\sigma_{i}^{y}}\right]^{\frac{1}{1-\sigma_{i}^{y}}}, \widetilde{Y}_{i t}^{*}=\left[\sum_{j \in \Omega_{i t}^{y *}}\left(\varphi_{i j t} Y_{i j t}\right)^{1-\sigma_{i}^{y}}\right]^{\frac{1}{1-\sigma_{i}^{y}}} S_{i j t}^{y *}=$ $\frac{P_{i j t} Y_{i j t}}{R_{i t}^{*}}$ for $j \in \Omega_{i t}^{y *}$, and $S_{i j t}^{y}=\frac{P_{i j t} Y_{i j t}}{R_{i t}}$.
} 
common goods, with the "Sato-Vartia weights" $\delta_{i j t}$. The second term is a weighted average of changes in (unobservable) product quality, again using the Sato-Vartia weights. Intuitively, increases in product quality tend to reduce the price index, other things equal. ${ }^{16}$ Together, the first and second terms are equal to the log change in the common-goods price index, $\widetilde{P}_{i t}^{*}$. The third term is an adjustment for entry and exit of products, first introduced by Feenstra (1994). Increases in product variety also tend to reduce the price index. ${ }^{17}$ Although the $\sigma_{i}^{y}$ term is unobservable, the $\chi_{i t-1, t}^{y}$ and $\chi_{i t, t-1}^{y}$ terms (which capture the common-goods shares of total firm revenues in periods $t-1$ and $t$ ) are observable.

Appendix A.1 further shows that the log change in the quantity index, $\widetilde{Y}_{i t}$, can also be expressed in a simple decomposition:

$$
\ln \left(\frac{\tilde{Y}_{i t}}{\widetilde{Y}_{i t-1}}\right)=\underbrace{\sum_{j \in \Omega_{i t}^{y *}} \delta_{i j t} \ln \left(\frac{Y_{i j t}}{Y_{i j t-1}}\right)+\sum_{j \in \Omega_{i t}^{y *}} \delta_{i j t} \ln \left(\frac{\varphi_{i j t}}{\varphi_{i j t-1}}\right)}_{=\ln \left(\widetilde{Y}_{\tilde{Y}_{i t}^{*}}^{*}\right.}+\frac{\sigma_{i}^{y}}{\sigma_{i}^{y}-1} \ln \left(\frac{\chi_{i t-1, t}^{y}}{\chi_{i t, t-1}^{y}}\right)
$$

where $\widetilde{Y}_{i t}^{*}$ is the quantity index for common goods. The first term is again the log of a Sato-Vartia index, this time for quantities, the second term captures improvements in product quality, and the third term captures increases in product variety.

It is worth noting that this within-firm CES approach nests the common approach of using firm revenues deflated by a sector-level price index to measure real ouput, as $\sigma_{i}^{y} \rightarrow \infty$. $^{18}$ In that sense, our aggregation method is strictly more general than the most commonly used one.

\footnotetext{
${ }^{16}$ Redding and Weinstein (2020), in a very different exercise, deal with the quality terms by assuming that the geometric average of product quality across products is time-invariant; our approach, by contrast, is to assume that they are orthogonal to the instruments we construct, as will be made clear below.

${ }^{17}$ For example, if no goods are dropped from $t-1$ to $t$ but new goods are introduced, then $\chi_{i t-1, t}^{y}=1>\chi_{i t, t-1}^{y}$, which, since $\sigma_{i}^{y}>1$ by assumption, implies a reduction in the price index. This reflects the fact that the utility function (1) embeds a taste for variety in the goods from a given firm.

${ }^{18}$ Put another way, as $\sigma_{i}^{y} \rightarrow \infty$ our approach would provide theoretical justification for the standard approach of deflating firm revenues by a sector-level price index. From (1) and (2), $\lim _{\sigma_{i}^{y} \rightarrow \infty} \tilde{Y}_{i t}=\sum_{j \in \Omega_{i t}^{y}} \varphi_{i j t} Y_{i j t}$ and $\lim _{\sigma_{i}^{y} \rightarrow \infty} \widetilde{P}_{i t}=\min _{j \in \Omega_{i t}^{y}}\left(P_{i j t} / \varphi_{i j t}\right)$. All goods purchased by the consumer have the same quality-adjusted price, call it $\breve{P}_{t}=P_{i j t} / \varphi_{i j t} \forall j \in \Omega_{i t}^{y}$; goods with higher quality-adjusted prices are not purchased. Then $R_{i t}=$ $\sum_{j \in \Omega_{i t}^{y}} P_{i j t} Y_{i j t}=\sum_{j \in \Omega_{i t}^{y}}\left(P_{i j t} / \varphi_{i j t}\right) \varphi_{i j t} Y_{i j t}=\breve{P}_{t} \widetilde{Y}_{i t}$. Hence as $\sigma_{i}^{y} \rightarrow \infty$, deflating $R_{i t}$ by $\breve{P}_{t}$ yields real output. Our approach is more general in that it is theoretically justified also for $\sigma_{i}^{y}<\infty$.
} 


\subsection{Production}

On the production side, we assume that real output, as defined above, is a function of capital, labor, and a firm-level CES materials aggregate, combining in Cobb-Douglas fashion:

$$
\widetilde{Y}_{i t}=\widetilde{M}_{i t}^{\beta_{m}} L_{i t}^{\beta_{\ell}} K_{i t}^{\beta_{k}} e^{\omega_{i t}+\eta_{i}+\xi_{t}+\epsilon_{i t}} \quad \text { where } \widetilde{M}_{i t}=\left[\sum_{h \in \Omega_{i t}^{m}}\left(\alpha_{i h t} M_{i h t}\right)^{\frac{\sigma_{i}^{m}-1}{\sigma_{i}^{m}}}\right]^{\frac{\sigma_{i}^{m}}{\sigma_{i}^{m}-1}}
$$

Here $h$ indexes material inputs, $\Omega_{i t}^{m}$ is the set of inputs purchased by the firm, $M_{i h t}$ is the quantity of each material input purchased, $L_{i t}$ is labor, and $K_{i t}$ is capital. We refer to $\alpha_{i h t}$ as input quality, recognizing that it may reflect physical attributes of the inputs or characteristics of the technology used to combine them in production. It captures any differences across inputs in how much one physical unit of the input contributes to the input aggregate. The assumption that the production function is Cobb-Douglas in capital, labor, and materials is standard in the literature. In principle, our approach could be extended to other functional forms (e.g. translog), although other forms would require additional instruments. As on the output side, we assume the the firm-specific elasticity of substitution between inputs is greater than unity, $\sigma_{i}^{m}>1$, which ensures that a firm consumes more of an input that increases in quality. In addition to being standard, this assumption is consistent with recent evidence at the micro level that intermediate inputs are typically substitutes (Dhyne et al., 2020b; Peter and Ruane, 2020); also, as discussed below, we believe that the assumption that inputs are subsitutes is particularly plausible in the subsectors we focus on. ${ }^{19}$

In the error term, $\omega_{i t}$ is a firm-specific "ex ante" productivity shock that firms observe before choosing inputs but that is unobservable to the econometrician; $\eta_{i}$ is a time-invariant firm effect; $\xi_{t}$ is a sector- or economy-level shock; and $\epsilon_{i t}$ is an "ex post" shock that is revealed after firms have chosen inputs (and hence is not "transmitted" to input choices). (We may also think of it as reflecting measurement error.) As is standard, we allow material inputs and labor to be adjustable in the short run and hence potentially correlated with the ex ante shock, $\omega_{i t}$, but assume that capital can be adjusted only with a lag of one period. We assume that the ex ante and ex post productivity shocks are uncorrelated with past values of inputs, but we allow for feedback from current shocks to future input choices (and from the ex ante shock to current choices). In the

\footnotetext{
${ }^{19}$ As on the output side, our method remains applicable, although with somewhat less intuitive implications, as long as $\sigma_{i}^{m}>0$. See Appendix A.2.
} 
language of Wooldridge (2010), we assume that the input choices are sequentially but not strictly exogenous. In addition, we assume that both $\omega_{i t}$ and $\epsilon_{i t}$ are serially uncorrelated. This assumption on $\omega_{i t}$ is stronger than usually imposed, but it can be tested with standard methods (Arellano and Bond, 1991), and we will not reject the null of no serial correlation. Formally, we assume:

$$
\begin{aligned}
& E\left(\omega_{i t} \mid \eta_{i}, K_{i t}, K_{i t-1} \widetilde{M}_{i t-1}, L_{i t-1}, \omega_{i t-1}, \epsilon_{i t-1} \ldots, K_{i 1}, \widetilde{M}_{i 1}, L_{i 1}, \omega_{i 1}, \epsilon_{i 1}\right)=0 \\
& E\left(\epsilon_{i t} \mid \eta_{i}, K_{i t}, \widetilde{M}_{i t}, L_{i t}, K_{i t-1}, \widetilde{M}_{i t-1}, L_{i t-1}, \omega_{i t-1}, \epsilon_{i t-1} \ldots, K_{i 1}, \widetilde{M}_{i 1}, L_{i 1}, \omega_{i 1}, \epsilon_{i 1}\right)=0
\end{aligned}
$$

where the conditioning on past values of the shocks implies a lack of serial correlation in the shocks. Here we assume that the firm effect, $\eta_{i}$, arguably captures within-firm persistence that might show up as serial correlation in models without fixed effects. ${ }^{20}$

It is important to note that the quality and variety of both outputs and inputs, represented by the quality terms $\varphi_{i j t}$ and $\alpha_{i h t}$ and the variety sets $\Omega_{i t}^{y}$ and $\Omega_{i t}^{m}$, may be chosen endogenously by firms. Researchers have proposed a number of frameworks to analyze such choices; see for instance Kugler and Verhoogen (2012) on quality, and Eckel and Neary (2010), Bernard et al. (2011) and Mayer et al. (2014) on variety. Here we do not adopt a particular model of how firms make these choices, nor do we assume that the firm behaves optimally in making them. We need only that the choices are uncorrelated with our internal and external instruments, discussed in Subsection 2.4 below.

The derivations of the price and quantity indexes on the input side are analogous to those on the output (i.e. demand) side. Given the production function (7) (which is also weakly separable, with homothetic aggregate $\left.\widetilde{M}_{i t}\right)$, the firm can be thought of as first choosing values of $M_{i h t}$ to minimize the cost of acquiring a given level of the aggregate input, $\widetilde{M}_{i t}$, and then choosing optimal values of $\widetilde{M}_{i t}, L_{i t}$ and $K_{i t}$, given the demand function, (3). Firms are assumed to be price-takers on input markets. As discussed below, we believe that this assumption is reasonable in the subsectors we focus on. ${ }^{21}$ Optimization in the first stage implies that the cost of purchasing

\footnotetext{
${ }^{20}$ Proxy-variable methods typically assume that $\omega_{i t}$ follows a Markov process, which allows for flexible patterns of serial correlation, but they do not allow for a firm effect, as discussed below.

${ }^{21}$ Estimation of production functions when producers have oligopsony power in input markets has recently been considered by Rubens (2020). Although market power in input markets could potentially be accommodated in our framework, we leave this extension to future work.
} 
one unit of the materials aggregate, $\widetilde{M}_{i t}$, is:

$$
\widetilde{W}_{i t}=\left[\sum_{h \in \Omega_{i t}^{m}}\left(\frac{W_{i h t}}{\alpha_{i h t}}\right)^{1-\sigma_{i}^{m}}\right]^{\frac{1}{1-\sigma_{i}^{m}}}
$$

This is the price index that sets $\widetilde{W}_{i t} \widetilde{M}_{i t}=E_{i t}^{m}$, where $E_{i t}^{m}$ is the firm's total expenditures on material inputs.

As on the output side, the CES assumption allows us to decompose input-price changes in a convenient way. Let $\Omega_{i t}^{m *}$ be firm $i$ 's common inputs between $t-1$ and $t$ (i.e. $\left.\Omega_{i t-1}^{m} \cap \Omega_{i t}^{m}\right), \widetilde{W}_{i t}^{*}$ and $\widetilde{M}_{i t}^{*}$ be the price and quantity indexes for common inputs, $E_{i t}^{m *}$ be the firm's expenditures on common inputs, $S_{i h t}^{m}$ be the firm's expenditure share on input $h$, among all inputs purchased by firm $i$, and $S_{i h t}^{m *}$ the corresponding share among common inputs. ${ }^{22}$ Appendix A.2 shows that the log change in the firm-specific input price level can be expressed as:

$$
\ln \left(\frac{\widetilde{W}_{i t}}{\widetilde{W}_{i t-1}}\right)=\underbrace{\sum_{h \in \Omega_{i t}^{m *}} \psi_{i h t} \ln \left(\frac{W_{i h t}}{W_{i h t-1}}\right)-\sum_{h \in \Omega_{i t}^{m *}} \psi_{i h t} \ln \left(\frac{\alpha_{i h t}}{\alpha_{i h t-1}}\right)}_{\ln \left(\widetilde{W}_{i t}^{*}\right.}-\frac{1}{\sigma_{i}^{m}-1} \ln \left(\frac{\chi_{i t-1, t}^{m}}{\chi_{i t, t-1}^{m}}\right)
$$

where:

$$
\psi_{i h t}=\frac{\left(\frac{S_{i h t}^{m *}-S_{i h t-1}^{m *}}{\ln S_{i h t}^{m *}-\ln S_{i h t-1}^{m *}}\right)}{\sum_{h \in \Omega_{i t}^{m *}}\left(\frac{S_{i h t}^{m *}-S_{i h t-1}^{m *}}{\ln S_{i h t}^{m *}-\ln S_{i h t-1}^{m *}}\right)}, \quad \chi_{i t, t-1}^{m}=\sum_{h \in \Omega_{i t}^{m *}} S_{i h t}^{m}, \quad \chi_{i t-1, t}^{m}=\sum_{h \in \Omega_{i t}^{m *}} S_{i h t-1}^{m}
$$

As for output prices, the first term is the log Sato-Vartia observable price change index for common goods; the second term is a weighted average of changes in input quality; and the third term is an adjustment for entry and exit of inputs.

As for output quantities, the change in the CES materials quantity aggregate can again be written as the sum of an observable Sato-Vartia quantity change index and unobservable terms

\footnotetext{
${ }^{22}$ That is, $\quad E_{i t}^{m *}=\sum_{h \in \Omega_{i t}^{m *}} W_{i h t} M_{i h t}, \quad \widetilde{W}_{i t}^{*}=\left[\sum_{h \in \Omega_{t, t-1}^{m *}}\left(W_{i h t} / \alpha_{i h t}\right)^{1-\sigma_{i}^{m}}\right]^{\frac{1}{1-\sigma_{i}^{m}}}, \quad \widetilde{M}_{i t}^{*}=$ $\left[\sum_{h \in \Omega_{t, t-1}^{m *}}\left(\alpha_{i h t} M_{i h t}\right)^{1-\sigma_{i}^{m}}\right]^{\frac{1}{1-\sigma_{i}^{m}}}, S_{i h t}^{m *}=\frac{W_{i h t} M_{i h t}}{E_{i t}^{m *}}$ for $h \in \Omega_{i t}^{m *}$, and $S_{i h t}^{m}=\frac{W_{i h t} M_{i h t}}{E_{i t}^{m}}$.
} 
capturing increases in variety and quality:

$$
\ln \left(\frac{\widetilde{M}_{i t}}{\widetilde{M}_{i t-1}}\right)=\underbrace{\sum_{h \in \Omega_{i t}^{m *}} \psi_{i h t} \ln \left(\frac{M_{i h t}}{M_{i h t-1}}\right)+\sum_{h \in \Omega_{i t}^{m *}} \psi_{i h t} \ln \left(\frac{\alpha_{i h t}}{\alpha_{i h t-1}}\right)}_{\ln \left(\frac{\widetilde{M}_{i t}^{*}}{\widetilde{M}_{i t-1}^{*}}\right)}+\frac{\sigma_{i}^{m}}{\sigma_{i}^{m}-1} \ln \left(\frac{\chi_{i t-1, t}^{m}}{\chi_{i t, t-1}^{m}}\right)
$$

where $\widetilde{M}_{i t}^{*}$ is the quantity index for common inputs. This approach again nests the standard approach of using expenditures deflated by a sector-level input price index as $\sigma_{i}^{m} \rightarrow \infty$; see footnote 18 .

\subsection{Deriving Estimating Equation}

To integrate the CES output and input quantity decompositions (6) and (12) into the production function, (7), it is convenient to restate the decompositions in levels. Let lower-case letters represent logs and $\triangle$ a change from $t-1$ to $t$. Summing the differences in (6) and (12) over time within firms, with firm-specific normalizations $\widetilde{y}_{i 0}$ and $\widetilde{m}_{i 0}$, we have:

$$
\begin{aligned}
& \widetilde{y}_{i t}=\underbrace{\widetilde{y}_{i 0}+\sum_{\tau=1}^{t} \sum_{j \in \Omega_{i \tau}^{y *}} \delta_{i j \tau} \Delta y_{i j \tau}}_{=: \widetilde{y}_{i t}^{S V}}+\underbrace{\sum_{\tau=1}^{t} \sum_{j \in \Omega_{i \tau}^{y *}} \delta_{i j \tau} \ln \left(\frac{\varphi_{i j \tau}}{\varphi_{i j \tau-1}}\right)}_{=: q_{i t}^{y}}+\underbrace{\left(\frac{\sigma_{i}^{y}}{\sigma_{i}^{y}-1}\right) \sum_{\tau=1}^{t} \ln \left(\frac{\chi_{i \tau-1, \tau}^{y}}{\chi_{i \tau, \tau-1}^{y}}\right)}_{=: v_{i t}^{y}}(13) \\
& \tilde{m}_{i t}=\underbrace{\tilde{m}_{i 0}+\sum_{\tau=1}^{t} \sum_{h \in \Omega_{i \tau}^{m *}} \psi_{i h \tau} \Delta w_{i h \tau}}_{=: \widetilde{m}_{i t}^{S V}}+\underbrace{\sum_{\tau=1}^{t} \sum_{h \in \Omega_{i \tau}^{m *}} \psi_{i h \tau} \ln \left(\frac{\alpha_{i h \tau}}{\alpha_{i h \tau-1}}\right)}_{=: q_{i t}^{m}}+\underbrace{\left(\frac{\sigma_{i}^{m}}{\sigma_{i}^{m}-1}\right) \sum_{\tau=1}^{t} \ln \left(\frac{\chi_{i \tau-1, \tau}^{m}}{\chi_{i \tau, \tau-1}^{m}}\right)}_{=: v_{i t}^{m}}
\end{aligned}
$$

where we define the new variables under the underbraces, $\widetilde{y}_{i t}^{S V}, q_{i t}^{y}, v_{i t}^{y}, \widetilde{m}_{i t}^{S V}, q_{i t}^{m}$, and $v_{i t}^{m}$, to be equal to the indicated summations. Note that in defining variables in this way, we set the quality and variety terms $q_{i t}^{y}, v_{i t}^{y}, q_{i t}^{m}$, and $v_{i t}^{m}$ to zero in the initial year and include the firm-specific normalizations as part of the "Sato-Vartia" quantity terms, $\widetilde{y}_{i t}^{S V}$ and $\widetilde{m}_{i t}^{S V}$.

Plugging these expressions into the production function, (7), and rearranging, we have:

$$
\widetilde{y}_{i t}^{S V}=\beta_{m} \widetilde{m}_{i t}^{S V}+\beta_{\ell} \ell_{i t}+\beta_{k} k_{i t}+\eta_{i}+\xi_{t}+u_{i t}
$$


where:

$$
u_{i t}=\left(\beta_{m} v_{i t}^{m}-v_{i t}^{y}\right)+\left(\beta_{m} q_{i t}^{m}-q_{i t}^{y}\right)+\omega_{i t}+\epsilon_{i t}
$$

This equation relates the Sato-Vartia output quantity index to the Sato-Vartia input quantity index (both observable, modulo the firm-specific normalizations), log capital, log labor, a firm effect, a year effect, and an error term that reflects variety and quality of outputs and inputs as well as the "ex ante" and "ex post" productivity shocks.

Writing the production function in this way helps to clarify two issues. The first is that simply using physical quantities for output and input may be problematic in a setting where quality or variety vary differently by firm over time, on the output side or the input side. The input choices $\widetilde{m}_{i t}^{S V}, \ell_{i t}$, and $k_{i t}$ may be correlated with the unobserved quality and variety terms, $q_{i t}^{m}, q_{i t}^{y}, v_{i t}^{m}$, and $v_{i t}^{y}$, generating what we call output- or input-quality bias, or output- or input-variety bias. To fix ideas, suppose that firms produce a single product using a single material input, in which case $\widetilde{y}_{i t}^{S V}$ and $\widetilde{m}_{i t}^{S V}$ simplify to the physical quantities of output and input and the variety terms drop out. If producing one unit of a higher-quality output requires more physical units of labor, with all else equal, then there will be a positive correlation between $\ell_{i t}$ and the $q_{i t}^{y}$ (and hence a negative correlation between $\ell_{i t}$ and the $-q_{i t}^{y}$ in the error term), generating a negative output-quality bias in the OLS estimate of $\beta_{\ell}$. Biases may also arise from purely exogenous shocks to product appeal or input quality, if such shocks affect firms' input choices — for instance, if a firm's product becomes fashionable for reasons unrelated to the firm's actions but it expands production to take advantage of the increased demand, or if a supplier improves the quality of a purchased input without changing the price and this induces the firm to increase output.

Among multi-product, multi-input firms, biases could arise from changes in variety. For instance, if import-tariff reductions increase the set of input varieties available and induce firms to increase the variety of inputs purchased, the variety of outputs produced, and total output, as suggested by Goldberg et al. (2010) and Bas and Paunov (2020), one would expect a positive correlation between $\widetilde{m}_{i t}^{S V}$ and $v_{i t}^{m}$ and a negative correlation between $\widetilde{m}_{i t}^{S V}$ and $-v_{i t}^{y}$, generating offsetting biases with ambiguous net effects. It is important to note that these quality and variety biases are distinct from transmission bias, and might be present even if one had a perfect proxy for the ex ante productivity term, $\omega_{i t}{ }^{23}$

\footnotetext{
${ }^{23}$ Note also that including a proxy for input quality alone, as in De Loecker et al. (2016), does not solve all of
} 
The second issue that equation (14) clarifies is why the scalar monotonicity assumption required by standard proxy-variable approaches is incompatible with our approach to aggregation. The leading proxy-variable approaches require a one-to-one relationship between a firm's underlying productivity and either investment or materials demand, conditional on other observables (Olley and Pakes, 1996; Levinsohn and Petrin, 2003; De Loecker, 2011; Doraszelski and Jaumandreu, 2013, 2018; Ackerberg et al., 2015; Gandhi et al., 2020) As noted by Ackerberg et al. (2015), in models with a firm effect (here $\eta_{i}$ ) in addition to the ex ante productivity term (here $\left.\omega_{i t}\right)$, this assumption is unlikely to hold, since the firm effect introduces a second dimension of heterogeneity between firms. ${ }^{24}$ In our case, we assumed the presence of a firm effect at the outset, in the production function, (7). But even if we had not, we would have to deal with the firm-specific normalizations $\widetilde{y}_{i 0}$ and $\widetilde{m}_{i 0}$ in (13), which we have folded into the levels of the observable SatoVartia quantity aggregates, $\widetilde{y}_{i t}^{S V}$ and $\widetilde{m}_{i t}^{S V}$. We impose a particular normalization in the second step of our estimation procedure below, but we feel that a strength of our approach is that we do not need to impose such an assumption in the first step when estimating the coefficients on materials and labor. We will pursue an approach more in the spirit of the panel-data literature, in part because it can more easily accommodate the fixed effect.

\subsection{Two-Step IV Estimation Procedure}

To estimate the production function, (14), we proceed in two steps, each implementing an IV model. In the first step, we first-difference to remove the firm effect and use lagged levels and external drivers of input price changes as instruments. We recover estimates of $\beta_{m}$ and $\beta_{\ell}$ from this step, but we treat $\beta_{k}$ as a nuisance parameter, in part because we do not believe there is sufficient signal in the within-firm changes in capital to estimate $\beta_{k}$ credibly. In the second step, we incorporate the first-step estimates of $\beta_{m}$ and $\beta_{\ell}$ in the levels equation and use the lagged difference of capital as an instrument for the level, in the spirit of the System GMM approach (Arellano and Bover, 1995; Blundell and Bond, 1998, 2000). To be clear about terminology: we refer the first step as the "differences" step and the second as the "levels" step; in each step, there is an IV model that has two stages.

\footnotetext{
the potential problems; there may still be correlation of physical input choices with output quality or with output or input variety.

${ }^{24}$ This issue is separate from the concern that firms may face heterogeneous constraints in input markets, which might break the monotonic relationship between productivity and materials or investment demand (Shenoy, forthcoming).
} 


\subsubsection{Differences (Step 1)}

A common approach to estimating an equation with a firm effect would be to implement a "within" estimator in which all variables are deviated from firm-specific means. But the within estimator would require the time-varying firm-specific productivity terms, $\omega_{i t}$ and $\epsilon_{i t}$, to be uncorrelated with all past and future values of the covariates - strict exogeneity in Wooldridge (2010)'s terminology — which would be violated if productivity shocks affect future input choices. Instead, we firstdifference to remove the firm effect, yielding an estimator that remains consistent under sequential exogeneity (which we have assumed in (8)). From (14),

$$
\triangle \widetilde{y}_{i t}^{S V}=\beta_{m} \triangle \widetilde{m}_{i t}^{S V}+\beta_{\ell} \triangle \ell_{i t}+\beta_{k} \triangle k_{i t}+\triangle \xi_{t}+\triangle u_{i t}
$$

where:

$$
\triangle u_{i t}=\left(\beta_{m} \triangle v_{i t}^{m}-\triangle v_{i t}^{y}\right)+\left(\beta_{m} \triangle q_{i t}^{m}-\triangle q_{i t}^{y}\right)+\triangle \omega_{i t}+\triangle \epsilon_{i t}
$$

Note that in addition to removing the firm effect, $\eta_{i}$, the first-differencing eliminates the firmspecific normalizations in (13), $\widetilde{y}_{i 0}$ and $\widetilde{m}_{i 0}$, from the Sato-Vartia terms, $\widetilde{y}_{i t}^{S V}$ and $\widetilde{m}_{i t}^{S V}$. We refer to (16) as our difference equation.

Ordinary least squares (OLS) estimation of (16) would be subject to the quality and variety biases discussed above as well as the familiar transmission bias (i.e. firms observe $\omega_{i t}$ before choosing the flexible inputs, inducing a positive correlation between $\triangle \omega_{i t}$ and $\triangle \widetilde{m}_{i t}^{S V}$ and $\triangle \ell_{i t}$ ). Additionally, in first differences even pre-determined variables will in general be correlated with the error term: $k_{i t}$, which appears in $\triangle k_{i t}$, may be correlated with $\omega_{i t-1}$ or $\epsilon_{i t-1}$, which appear in $\triangle u_{i t}$. To address these concerns, we seek instruments that are correlated with $\triangle \widetilde{m}_{i t}^{S V}, \triangle \ell_{i t}$ and $\triangle k_{i t}$ and uncorrelated with the error term, $\triangle u_{i t}$. If $u_{i t}$ is serially uncorrelated in levels, as we have assumed, then $u_{i t-2}$ and further lags are uncorrelated with $\triangle u_{i t}$ and input levels in $t-2$ and further back are valid instruments for $\Delta \widetilde{m}_{i t}^{S V}, \Delta \ell_{i t}$ and $\triangle k_{i t}$. Below we will implement standard tests for serial correlation from Arellano and Bond (1991) and find that we do not reject the null hypothesis of no serial correlation. ${ }^{25}$

\footnotetext{
${ }^{25}$ Note that our approach differs from standard System GMM in the assumption on the productivity shocks. Blundell and Bond $(1998,2000)$ assume that the ex ante productivity shocks follow an AR(1) process and quasidifference to purge the serial correlation prior to estimation. Under the (testable) assumption of no serial correlation, this quasi-differencing is not necessary.
} 
A widely recognized concern with using lagged levels as instruments, however, is that they may be only weakly correlated with current differences (Griliches and Mairesse, 1998; Blundell and Bond, 1998, 2000; Bun and Windmeijer, 2010; Hayakawa and Qi, 2020). ${ }^{26}$ Including further and further lags may exacerbate the weak-instrument problem. Testing for weak instruments is complicated here by the presence of multiple endogenous covariates and the potential for heteroskedastic errors (which we would not feel justified in assuming away). This is a frontier area of econometric theory and there is no consensus in the literature on the right diagnostic tests to use in such cases. ${ }^{27}$ Two tests are commonly reported in practice. Sanderson and Windmeijer (2016) propose an improved version of a test first suggested by Angrist and Pischke (2009), which is appropriate for estimation and inference on each of multiple endogenous regressors, as we are interested in here. ${ }^{28}$ Also commonly reported is the Kleibergen and Paap (2006) Wald statistic, an analogue of the Cragg and Donald (1993) statistic applicable in non-homoskedastic settings. ${ }^{29}$ We will report both the Sanderson-Windmeijer and Kleibergen-Paap Wald statistics below. The statistics will give reason to be concerned about the weakness of the internal instruments.

Our strategy for strengthening the instrument set is to incorporate external instruments capturing exogenous variation in the prices of materials and labor. To construct the materials-price instrument, we proceed in two steps, taking advantage of detailed Colombian trade-transactions data merged with the Colombian manufacturing survey. We first use real-exchange-rate movements to predict import-price movements at the product-year level. ${ }^{30}$ We then use information on the product composition of each firm's imports to aggregate the predictions to the firm-year level. To ensure that the predicted import index is uncorrelated with $u_{i t-1}$, which appears in $\triangle u_{i t}$ in (16), we run "leave one out" regressions (one for each firm, omitting that firm's imports) to predict import-price changes and we use import product composition from $t-2$ to do the

\footnotetext{
${ }^{26}$ In the setting of cross-country growth regressions, Bazzi and Clemens (2013) and Kraay (2015) show that the instruments used in difference and system GMM estimators are weak and can suggest misleading inferences. See also the review by Bun and Sarafidis (2015).

${ }^{27}$ In a recent state-of-the-art review, Andrews et al. (2019) recommend the test of Montiel Olea and Pflueger (2013) in cases with a single endogenous regressor, but have no recommendation in cases with multiple endogenous regressors; see their footnote 4.

${ }^{28}$ The Sanderson-Windmeijer statistic adjusts for the fact that the endogenous covariates may themselves be highly correlated. The theoretical justification for it relies on an assumption of homoskedastic errors, but it is commonly reported even in non-homoskedastic settings.

${ }^{29}$ Although the Kleibergen and Paap (2006) Wald statistic is sometimes compared to the Stock and Yogo (2005) critical values (see e.g. Baum et al. (2007)), the validity of this comparison is unclear in the non-homoskedastic case, since the critical values are calculated under the assumption of homoskedasticity.

${ }^{30}$ Exchange-rate movements have previously been used as a source of identification in production-function estimation by Park et al. (2010), who use them as a source of variation in demand from export markets.
} 
aggregation.

To be precise, we begin by defining real exchange rates (RERs) as:

$$
R E R_{o t}=N E R_{o t}\left(\frac{C P I_{o t}}{C P I_{C o l, t}}\right)
$$

where $o$ indexes import origins, $N E R_{o t}$ is the nominal exchange rate (Colombian pesos/foreign currency), $C P I_{o t}$ is the consumer price index (CPI) in the origin, and $C P I_{C o l, t}$ is the CPI of Colombia. Defined in this way, a real appreciation in country $o$ is reflected in an increase in $R E R_{o t}$. We consider the top 100 origins by Colombian import volume and label this set $\mathcal{O}$. We use $n$ to index products defined at the 8-digit trade classification level, which do not map cleanly to products in the Colombian industrial classification, indexed by $j$ and $h$ above. We exclude machinery and equipment, which could arguably be considered capital rather than material imports; we also exclude petroleum and other mineral fuels. ${ }^{31}$ For a particular imported input $n$, we calculate an average log RER change separately for each firm in our data, weighting by imports but leaving out the firm's own imports:

$$
\triangle \overline{r e r}_{n t,-i}=\sum_{o \in \mathcal{O}} \zeta_{\text {ont }-1,-i} \triangle \ln \left(R E R_{o t}\right), \quad \text { where } \zeta_{\text {ont }-1,-i}=\frac{\mathcal{I}_{\text {ont-1,-i }}}{\sum_{o \in \mathcal{O}} \mathcal{I}_{\text {ont }-1,-i}}
$$

Here $\mathcal{I}_{\text {ont }-1,-i}$ is the "leave-one-out" value of imports of product $n$ from origin $o$ in period $t-1$ for all firms except $i$. We then use these product-level average real-exchange-rate changes to predict import price changes at the product-year level, using the regression:

$$
\triangle w_{n t,-i}^{i m p}=\gamma_{s t} \triangle \overline{r e r}_{n t,-i}+\rho_{s t}+\eta_{n t}
$$

where $\triangle w_{n t,-i}^{i m p}$ is the change in import $n$ 's log import price (averaged across origins using import weights) for imports of all firms except $i,{ }^{32}$ and $\rho_{s t}$ is a sector-year effect. In our preferred specification, $s$ indexes two digit trade sectors and we allow the coefficient on the exchangerate term to vary by two-digit trade sector and year. ${ }^{33}$ We run this leave-one-out regression

\footnotetext{
${ }^{31}$ That is, we exclude Harmonized System 2-digit categories 27, 84 and 85.

${ }^{32}$ That is, $\triangle w_{n t,-i}^{i m p}=\sum_{o \in \mathcal{O}} \zeta_{\text {ont }-1,-i} \triangle w_{\text {ont },-i}^{i m p}$, where $\zeta_{\text {ont }-1,-i}$ is defined as in (18).

${ }^{33}$ In principle, we could include lags of the average real-exchange-rate changes in (19). But consistent with the literature on exchange-rate pass-through (see e.g. Campa and Goldberg (2005)), we have found that the effect of RER changes on import prices decays relatively quickly, within one year, and including further lags has little effect on the strength of our instrument, so we do not include them here.
} 
separately for each firm $i$ (using data from all firms in the customs data that can be linked to the manufacturing survey, not just those in the rubber and plastics sectors) and recover the predicted values, $\triangle \widehat{w}_{n t,-i}^{i m p}$.

We then use firm $i$ 's product-level import shares as weights in constructing the average predicted import price change at the firm level:

$$
\triangle \widehat{\bar{w}}_{i t}^{i m p}=\sum_{n \in \mathcal{N}} \theta_{i n t-2} \triangle \widehat{w}_{n t,-i}^{i m p}, \quad \text { where } \theta_{i n t-2}=\frac{I_{i n t-2}}{\sum_{n \in \mathcal{N}} I_{i n t-2}}
$$

Here $I_{\text {int-2 }}$ is imports by firm $i$ of product $n$ in period $t-2$ and $\mathcal{N}$ is the set of all imported products. For firms that did not import in $t-2$, we set $\triangle \widehat{\widehat{w}}_{i t}^{i m p}=0$. This average predicted import price change at the firm level, $\triangle \widehat{\bar{w}}_{i t}^{i m p}$, is our external instrument for $\triangle \widetilde{m}_{i t}^{S V}$ in (16). ${ }^{34}$

To construct an external instrument for labor, we exploit the fact that the minimum wage in Colombia is high relative to the wage distribution and that it rose sharply over our sample period, especially in 1994-1999 and 2003-2009. (See Subsection 3.3 for institutional background.) We first construct a measure of the "bite" of the minimum wage - how binding it is expected to be on a particular firm — defined as:

$$
B_{i t}=\frac{M W_{t}}{W_{i t}^{\ell}}
$$

where $M W_{t}$ is the national minimum wage (defined for monthly earnings and annualized multiplying by 12) and $W_{i t}^{\ell}$ is firm-level average annual earnings per worker for permanent workers, calculated as the firm-level annual wage bill divided by average employment. Defined in this way, $B_{i t}<1$ and the closer the firm average wage is to the national minimum wage, the larger is $B_{i t}$. We interact this measure of bite with the change in the national minimum wage, using bite from $t-2$ (again to avoid correlation with $u_{i t-1}$, which appears in $\triangle u_{i t}$ in (16)):

$$
\triangle z_{i t}=B_{i t-2} * \triangle \ln \left(M W_{t}\right)
$$

This predicted wage change, $\triangle z_{i t}$, serves as an instrument for $\triangle \ell_{i t}$ in (16). Other studies that have followed this strategy of interacting minimum wage changes with differences in their bite include Card (1992), Stewart (2002), and Cengiz et al. (2019).

\footnotetext{
${ }^{34}$ Exchange-rate movements may also affect export prices. We address this concern by constructing an analogous predicted export price index and including it as an additional covariate; see Section 5.2 below.
} 
It is well known that the estimation of the coefficient on capital is problematic in firstdifferenced models, and indeed in any model that includes a firm effect. For example, in a first-differenced model using lagged levels as instruments, Ornaghi (2006) finds a negative coefficient on capital. Using a within estimator, Söderbom and Teal (2004) also find a negative relationship. It is common to attribute low estimates of the capital coefficient to measurement error in capital, the effect of which is exacerbated by transformations to remove the firm effect (Griliches and Mairesse, 1998; Ackerberg et al., 2015). In the Colombian manufacturing census, we do not observe capital utilization, and it seems likely that the capital measure we are able to construct, while standard, is a very noisy measure of capital in use. It may also be that in the presence of adjustment costs for capital, with firms investing in a lumpy way and the returns to capital accruing over long periods, changes in capital are not likely to show up immediately in changes in output (Griliches and Mairesse, 1998). Griliches and Mairesse (1998) recommend looking at longer differences, to reduce the role of noisy year-to-year fluctuations. But as noted above (footnote 33), the real-exchange-rate fluctuations that are the main source of exogenous variation in our predicted-import-price instrument have an effect on prices only in the relatively short term, typically 1-2 quarters, and the instrument has little explanatory power over longer periods. If we had an external instrument that generated large changes in capital on a year-by-year basis, it would help to improve the estimation of the capital coefficient, but we have not found such an instrument. In light of these issues, we conclude that we do not have sufficient signal in year-on-year capital changes to estimate $\beta_{k}$ well in first-differences. In the first step, we focus on estimating $\beta_{m}$ and $\beta_{\ell}$ and treat $\beta_{k}$ as a nuisance parameter. In the next subsection, we present a different strategy for estimating $\beta_{k}$, in levels, incorporating "between" variation.

The key identifying assumptions for this first step, in differences, are that the instruments the external instruments, $\triangle \widehat{\bar{w}}_{i t}^{i m p}$ and $\triangle z_{i t}$, and the internal instruments, $\widetilde{m}_{i t-2}^{S V}, \ell_{i t-2}$, and $k_{i t-2}$ - are uncorrelated with the error term in (16), $\triangle u_{i t}$. Under these assumptions, we can recover consistent estimates of output elasticities with respect to materials and labor, $\widehat{\beta}_{m}$ and $\widehat{\beta}_{\ell}$. If one is only interested in $\widehat{\beta}_{m}$ and/or $\widehat{\beta}_{\ell}$, for instance to use in constructing markups in the method of Hall (1986) and De Loecker and Warzynski (2012), then one can stop at this step. 


\subsubsection{Levels (Step 2)}

In the second step, we proceed in the broad spirit of System GMM (Arellano and Bover, 1995; Blundell and Bond, 1998, 2000) in using lagged differences as instruments in a levels equation. ${ }^{35}$ The System GMM assumption that lagged differences are uncorrelated with the firm effect is equivalent to assuming that the correlation of the level of the inputs and the firm effect is constant over time, which Bun and Sarafidis (2015) refer to as the "constant correlated effects" assumption. Here, because of the availability of the external instruments in Step 1, we need this assumption only for capital, not for materials or labor. That is, we assume:

$$
E\left(k_{i t} \eta_{i}\right)=c_{i}
$$

for some (potentially firm-specific) constant $c_{i}$. This assumption rules out correlation between a firm's time-invariant productivity and the evolution of its capital stock over time and is clearly restrictive. But we believe that it is plausible in our setting, where much of the within-firm variation appears to be due to measurement error. ${ }^{36}$

To proceed, we also need to take a stand on the firm-specific normalizations, $\widetilde{m}_{i 0}$ and $\widetilde{y}_{i 0}$, in (13). This amounts to choosing a base year for the firm-specific output and input price indexes, $\widetilde{P}_{i t}$ and $\widetilde{W}_{i t}$. Here we assume that these indexes are equal to unity in the first year that a firm appears in our data. In logs, since $r_{i t}=\widetilde{y}_{i t}+\widetilde{p}_{i t}$ in every period, setting $\widetilde{p}_{i 0}=0$ implies $\widetilde{y}_{i 0}=r_{i 0}$; that is, the log output quantity index in a firm's first year in the panel is set equal to log revenues. Similarly, on the input side, setting $\widetilde{w}_{i 0}=0$ implies $\widetilde{m}_{i 0}=e_{i 0}$; the log input quantity index is set equal to log expenditures. These choices for the firm-specific normalizations preserve the cross-sectional variation in sales and expenditures present in the initial year for each firm.

Using $\widehat{\beta}_{m}$ and $\widehat{\beta}_{\ell}$ from Step 1 and recalling that $\widetilde{y}_{i 0}$ and $\widetilde{m}_{i 0}$ are included in the definitions of $\widetilde{y}_{i t}^{S V}$ and $\widetilde{m}_{i t}^{S V}$, equation (14) can be rewritten as:

$$
\widetilde{y}_{i t}^{S V}-\widehat{\beta}_{m} \widetilde{m}_{i t}^{S V}-\widehat{\beta}_{\ell} \ell_{i t}=\beta_{k} k_{i t}+\xi_{t}+\breve{u}_{i t}
$$

\footnotetext{
${ }^{35}$ Despite this similarity, our approach differs from Blundell and Bond (2000) in that we use a different set of instruments, we do not allow for for serial correlation in ex ante productivity (and hence do not quasi-difference to eliminate it), and we do not estimate the difference and levels equations simultaneously by GMM. See also Section 6.

${ }^{36}$ Assumption (23) would also be justified if current investment were a function of current and past innovations in productivity, i.e. $\omega_{i t}, \omega_{i t-1}, \ldots, \omega_{i 0}$, but not the fixed effect, $\eta_{i}$.
} 
where the error term now includes the firm effect, $\eta_{i}$, and terms arising from estimation error in the first-step estimates:

$$
\breve{u}_{i t}=\eta_{i}+\left(\beta_{m}-\widehat{\beta}_{m}\right) \widetilde{m}_{i t}^{S V}+\left(\beta_{\ell}-\widehat{\beta}_{\ell}\right) \ell_{i t}+\left(\beta_{m} v_{i t}^{m}-v_{i t}^{y}\right)+\left(\beta_{m} q_{i t}^{m}-q_{i t}^{y}\right)+\omega_{i t}+\epsilon_{i t}
$$

We assume that the lagged difference in capital, $\triangle k_{i t-1}$, is uncorrelated with the quality and variety terms, $q_{i t}^{m}, q_{i t}^{y}, v_{i t}^{m}$ and $v_{i t}^{y}$. Under this assumption and the constant correlated effects assumption, (23), $\triangle k_{i t-1}$ is a valid instrument for $k_{i t}$ in (24). ${ }^{37}$ Although the first-step estimation

errors in $\widehat{\beta}_{m}$ and $\widehat{\beta}_{\ell}$ show up in $\breve{u}_{i t}$, the consistency of the first-step estimates implies that they will not render the second-step estimates inconsistent. ${ }^{38}$ They may, however, need to be taken into account in estimating the standard error on $\hat{\beta}_{k}$. As explained in more detail in Appendix A.3, if there is no correlation between $\triangle k_{i t-1}$ and $\widetilde{m}_{i t}^{S V}$ or $\ell_{i t}$, then no correction of the standard errors is required, but if there is correlation, then a correction needs to be applied. Below we report both the uncorrected and the corrected standard errors.

If the model is specified correctly, then estimating it in two steps potentially involves a loss of efficiency relative to simultaneous GMM estimation. But as recently pointed out by Kripfganz and Schwarz (2019) in a related context, an advantage of the two-step approach is that our firststep estimates of $\beta_{m}$ and $\beta_{\ell}$ are robust to mis-specification in the second stage, and in particular to violations of the constant-correlated-effects assumption, (23).

\section{Data, Institutional Background, and Descriptive Statistics}

This section describes the main datasets we use, reviews the institutional background on the minimum wage in Colombia, explains the motivation for our choice of subsectors, and presents descriptive statistics for our sample. Additional details are in Appendix B.

\footnotetext{
${ }^{37}$ We also present results using $\triangle k_{i t-2}$ as the instrument for $k_{i t}$.

${ }^{38}$ This follows from the facts that $\operatorname{plim}_{I \rightarrow \infty} \frac{1}{I} \sum_{i} \triangle k_{i t-1}\left[\left(\beta_{m}-\widehat{\beta}_{m}\right) \widetilde{m}_{i t}^{S V}+\left(\beta_{\ell}-\widehat{\beta}_{\ell}\right) \ell_{i t}\right]=$ $\operatorname{plim}_{I \rightarrow \infty} \frac{1}{I}\left(\triangle k_{i t-1} \widetilde{m}_{i t}^{S V}\right) \cdot \operatorname{plim}_{I \rightarrow \infty}\left(\beta_{m}-\widehat{\beta}_{m}\right)+\operatorname{plim}_{I \rightarrow \infty} \frac{1}{I}\left(\triangle k_{i t-1} \ell_{i t}\right) \cdot \operatorname{plim}_{I \rightarrow \infty}\left(\beta_{\ell}-\widehat{\beta}_{\ell}\right)$ (where $I$ is the total number of firms) and, if the first-step estimates are consistent, then $\operatorname{plim}_{I \rightarrow \infty}\left(\beta_{m}-\widehat{\beta}_{m}\right)=\operatorname{plim}_{I \rightarrow \infty}\left(\beta_{\ell}-\widehat{\beta}_{\ell}\right)=0$. See Section 4 of Kripfganz and Schwarz (2019) and in particular their footnote 19.
} 


\subsection{Annual Manufacturing Survey}

We use information on sales, employment, wages, capital stock, inputs and outputs from the Encuesta Anual Manufacturera (EAM, Annual Manufacturing Survey), collected by the Colombian statistical agency, DANE. Data are reported at the plant level, and we aggregate them to the firm level - the level at which we observe imports and exports from trade transactions records (see below). In the sectors we focus on, nearly all firms have just one plant. We focus on data from the period 1994-2009. ${ }^{39}$ Given that we will need at least two lags in our baseline specifications, our main period of analysis is 1996-2009.

The survey contains information on the values and physical quantities of all outputs produced and inputs consumed by each plant at the level of eight-digit product categories. ${ }^{40}$ Because the survey is used to construct producer price indexes, DANE pays careful attention to the physical units of measurement for each product, and a given product is always reported using the same units. We calculate product prices at the firm level as unit values: $P_{i j t}=R_{i j t} / Y_{i j t}$, where $R_{i j t}$ is the value of product $k$ produced by firm $i$ in year $t$ and $Y_{i j t}$ the corresponding quantity. Input prices are calculated analogously. Further details, including on the construction of capital stock, which uses a standard perpetual-inventory method, are in Appendix B.1. The fact that the survey contains, in principle, information on all material inputs is important because it responds to a criticism of IV methods, for instance by Ackerberg et al. (2015), that the exclusion restrictions for input-price instruments are likely to be violated if one observes only a subset of inputs.

\subsection{Customs Records and Exchange Rates}

The customs data contain information from the administrative records filled out by every Colombian importer or exporter for each international transaction, collected by the Colombian customs agency, DIAN. Information is available at the level of the firm, product code ( 8 digit), year, and country of origin (for imports) or destination (for exports). Imports and exports by the firm are merged with the EAM manufacturing data using firm identifiers according to the procedures established by DANE. Further details are in Appendix B.2.

\footnotetext{
${ }^{39}$ Prior to 1994 , the EAM used different plant identifiers and it is often difficult to track plants over time. Although we use data from 1992-1993 when available in constructing firm-level capital stock, we do not focus on these years in the main analysis. Using procedures established by DANE to protect the confidentiality of the data, it is possible to link the customs data (see below) to the EAM only until 2009.

${ }^{40}$ The survey also reports information on outputs sold and inputs purchased, but we use the information on production and consumption to avoid timing issues that arise because firms hold inventories.
} 
To calculate real exchange rates (RERs) by trading partner, we use nominal exchange rates and consumer price indexes (CPIs) from the International Financial Statistics (IFS) of the International Monetary Fund. ${ }^{41}$ Appendix Figure A1 depicts the movements in real exchange rates (defined such that an increase reflects a real appreciation in the trading partner) for the 12 countries from which rubber and plastics producers purchased the most imports during the period of our analysis. We see that several of the most important import origins had significant RER fluctuations. Venezuela and Mexico, both major oil producers, had large real appreciations in 1995-2000 and large real depreciations subsequently. Indonesia suffered a major crisis accompanied by sharp real devaluation in 1997 (as did Argentina (not pictured) in 2001). Even the US and Eurozone countries, which were less volatile overall, experienced non-trivial variation in the RER relative to Colombia.

\subsection{Minimum Wage}

Despite wide variation in local labor market conditions, Colombia has a single national minimum wage. Over our study period, it was one of the highest in Latin America as a share of the median wage, and it increased significantly in real terms (Maloney and Nuñez Mendez, 2004; Mondragón-Vélez et al., 2010). As required by the Colombian constitution, increases for the coming year are negotiated in December by a tripartite commission including representatives from government, employer associations, and labor organizations. Prior to 1999, the target was commonly understood to be predicted inflation plus predicted productivity growth (Maloney and Nuñez Mendez, 2004; Hofstetter, 2006). In 1999, because of a recession, predicted inflation greatly exceeded actual inflation and the real value of the minimum wage increased by $7 \%$. In addition, the Constitutional Court in Colombia ruled in 1999 that the minimum wage increase could not be lower than the previous year's inflation. As a result, the real value of the minimum wage continued to rise after 2000, remaining above $90 \%$ of the median wage through the end of our study period (Mondragón-Vélez et al., 2010). Appendix Figure A2 shows the steady increase of the real minimum wage over our study period. To illustrate the bite of the minimum wage, Appendix Figure A3 plots a histogram of real wages in 1998 for individuals who report working in firms with 10 or more employees in manufacturing in a Colombian household survey, the Encuesta Nacional de Hogares. The solid and dashed vertical lines represent the 1998 and 1999 minimum

\footnotetext{
${ }^{41}$ For a few countries with no information in the IFS, we gathered data directly from their central banks.
} 
wages, respectively. We see that there was extensive bunching of wages at the minimum in 1998, and that a large share of manufacturing workers was directly affected by the 1999 minimum wage increase. The minimum wage is often used to index the wages of employees who earn above the minimum; as a consequence, increases in the real minimum wage are likely to have an effect on wages throughout the distribution (Mondragón-Vélez et al., 2010). Researchers have previously found disemployment effects of the minimum wage in Colombia, in contrast to several other countries in the region (Bell, 1997; Maloney and Nuñez Mendez, 2004); below we will also find negative employment effects.

\subsection{Choice of Subsectors and Descriptive Statistics}

Our method is most applicable in industries that meet several criteria. First, the ability to accommodate endogenous quality and variety choices is most valuable in sectors producing differentiated products, particularly those with substantial quality variation. Second, given that we assume that firms are price-takers in input markets, our method is most applicable in industries in which inputs, although they may differ in quality, are relatively non-specialized and substitutable within quality categories. Third, for our instrument for materials to be relevant, a substantial share of inputs in the industry must be imported, such that real-exchange-rate fluctuations have a significant effect on the input prices faced by firms.

In choosing subsectors that fit these criteria, we face a familiar trade-off. On one hand, we would like sample sizes to be as large as possible in order to increase the precision of our estimates. This clearly matters in our setting where the weakness of instruments is a concern. On the other hand, the wider the net that we cast, the more heterogeneous the included firms are likely to be. This trade-off is well recognized in the literature; see for instance the discussion in Dhyne et al. (2020a, Sec. 4.3). The issue is particularly salient because, as is standard in the literature, we will treat all firms in a single broad sector as having the same production-function coefficients.

Our approach in this paper is to focus on firms producing rubber and plastic products. These subsectors are adjacent in the ISIC revision 2 classification (with 3-digit codes 355 and 356, respectively) and are often classified together in a 2-digit sector, as for instance in Sector 36 ("Rubber and Plastic Products") of the U.N. Central Product Classification (CPC). Table 1 reports their main 8-digit outputs. For rubber, the main product is tires of different sorts. These can be understood to be differentiated products: they are sold under brand names - Goodyear 
and Michelin tires are produced in Colombia, for instance - and often for fairly specialized uses. For plastics, there is less concentration on a single type of product; output is distributed across various types of tubing, bags, sheets, films, and containers. But again, the products of the sector are typically differentiated and often targeted for specialized uses.

By contrast, the inputs of both subsectors can be viewed as commodities, or at least commoditylike - highly substitutable across suppliers even if they have quality differences. Table 2 reports the main 8-digit inputs. For rubber, the most important input is natural latex, from the bark of rubber trees. The second-most important input category is "rare metals in primary forms" (CPC product code 3423112) which includes carbon black, a form of carbon used as a filler in tires. ${ }^{42}$ For the plastics subsector, the most important inputs are raw forms of different common plastics — polyethylene (PET), polypropylene (PP), polyvinyl chloride (PVC), polystyrene, and others - often purchased in the form of pellets. Although the pellets may vary in their chemical properties, these differences are typically noted on the packaging. Within a given chemical specification, pellets from different producers and origin countries are typically considered to be highly substitutable. There may be other dimensions of supply relationships that cannot be observed ex ante, for instance timeliness of delivery or willingness of supplier to extend trade credit. But to a first approximation we believe it is reasonable to treat the main inputs in rubber and plastics as highly substitutable, with observable quality differences.

As is evident in Table 2, a large share of inputs in both subsectors is imported. In rubber products, almost all natural latex is imported, as is a substantial share of carbon black and other inputs. In plastics, a majority of PET and 20-25\% of PVC and polystyrene are imported. These import shares are from the EAM data and hence represent shares of inputs imported directly by firms. To the extent that firms purchase imported goods from local intermediaries, they understate the true import shares of the inputs. Both rubber and plastics are among the more import-intensive 3-digit subsectors in the EAM data.

In short, because both rubber and plastics products producers use highly substitutable inputs, a large share of which are imported, to produce horizontally and vertically differentiated products, we believe that they are well-suited to our method.

In selecting the estimation sample, we require that a firm have complete data on capital,

\footnotetext{
${ }^{42}$ The 5-digit product code 32431, harmonized at the international level, includes "inorganic oxygen compounds of boron, silicon and carbon." The final two digits of the CPC product code are Colombia-specific. We have confirmed in the firm-level imports data (using an alternative 8-digit product classification) that the main input in this category is carbon black and other forms of carbon.
} 
labor, materials, and outputs for at least six consecutive years. This requirement is helpful to ensure that the perpetual-inventory method generates a sensible measure of capital stock. It also ensures that our sample of firms does not change as we modify the number of lags required in different specifications. Given that the EAM data are available beginning in 1994 and that in all specifications we will need at least two lags, our sample covers the years 1996-2009. We are left with 362 firms in an unbalanced panel, with 11.73 observations per firm on average. Table 3 presents summary statistics on this baseline sample. We see that the two subsectors are comparable on many dimensions. Rubber firms spend a large share of expenditures on imports and earn a larger share of revenues from exports, but employment averages about 100 in both subsectors and wages and output are similar.

To explore the robustness of our results to the definition of the subsectors of interest, in the appendix we will report results for two alternative samples. In the first, we remove rubber products and focus exclusively on plastics, the larger of the two subsectors. In the second, we keep both rubber and plastics and add glass products (ISIC rev. 2 subsector 362), a subsector that also arguably satisfies the criteria of relatively substitutable inputs, high imported input share, and differentiated outputs. Descriptive statistics on the glass products subsector are reported in Appendix Tables A1-A2.

\section{Baseline Results}

This section reports the results of the estimation strategy laid out in Section 2. For comparison purposes, we begin by presenting the "naive" OLS and first-difference (FD) results, and then move on to our two-step IV (TSIV) method.

\section{1 "Naive" OLS and FD Models}

Panel A of Table 4 presents estimates using sales as the measure of output and material expenditures as the measure of input use, with both deflated by sector-level deflators. The OLS estimates in Columns 1 and 2, without and with year effects respectively, appear to be reasonable, and are roughly consistent with constant returns to scale, as is typically expected (see e.g. Bartelsman and Doms (2000)). Columns 3 and 4 report first-difference (FD) estimates, corresponding to equation (16) without instruments. Relative to the OLS estimates, the materials coefficients are 
significantly lower, the labor coefficients remain roughly unchanged, and, strikingly, the capital coefficients drop almost to zero. The latter fact illustrates a point made above, that transformations to remove firm effects lead to severe attenuation of the capital coefficient; this problem is not specific to our TSIV method.

Panel B of Table 4 again report OLS and FD estimates, but using the Sato-Vartia quantity aggregates for output and materials. In Columns 1 and 2, we have imposed the firm-specific normalizations for $\widetilde{y}_{i 0}$ and $\widetilde{m}_{i 0}$ discussed in Section 2.4.2 above, effectively using each firm's first year in the unbalanced panel as the base year for the firm-specific output and input deflators. Overall, we see significant differences in the OLS estimates - in particular, deflating at the firm level reduces the OLS materials coefficient and raises the capital coefficient — but the FD estimates in Columns 3 and 4 are quite similar to those using sales and expenditures in Panel A.

\subsection{Differences (Step 1) Results}

In this step, we estimate our difference equation (16) using instruments for the changes in input choices. Table 5 reports the first stage for different sets of instruments. Columns 1-3 use only internal instruments, and in particular only lagged levels of inputs from period $t-2$. The coefficient estimates are plausible, with lagged levels negatively associated with current changes. But the instruments are weak: the Sanderson and Windmeijer (2016) (SW) F-statistics are below the ruleof-thumb level of 10 (as are the conventional F-statistics for materials and labor), and although the Kleibergen-Paap (KP) LM test easily rejects the null of underidentification, the KP Wald statistic for weak instruments is below 1. In Appendix Table A3, we show that this weak instrument issue is not resolved by including further lags as instruments in a GMM model. ${ }^{43}$

To improve the explanatory power of the first stage of this step, we turn instead to our external instruments. As described in Subsection 2.4.1 above, the first step in the construction of the firm-level predicted import-price index, $\triangle \widehat{\widehat{w}}_{i t}^{i m p}$ from (20), is to estimate the relationship between RER movements and import prices given by (19), leaving out the data from one firm at a time. (In running these regressions, we include all firms in the DIAN imports data that can

\footnotetext{
${ }^{43}$ Appendix Table A3 reports results from GMM estimation of our difference equation (16), where further lags have been added "GMM-style" (Holtz-Eakin et al., 1988; Roodman, 2009), using available lags and allowing separate coefficients in each period. Lags are included just to $t-2$ in Column 1 , to $t-3$ in Column 2 , and to the firm's initial year in Column 3. The Kleibergen-Paap Wald statistic remains below 2 and the Sanderson-Windmeijer F statistics are all below 3.5. However, the materials and labor coefficient estimates are similar to those using our TSIV procedure presented below.
} 
be linked to the EAM manufacturing data, not just those in the rubber and plastics subsectors.) This generates 362 sets of coefficient estimates, one for each firm in our sample, where each set contains a separate coefficient for each sector-year. In Appendix Figure A4, we report sector-level average coefficients, averaging across firms and across years (with standard errors also averaged across firms and years). Although there is some heterogeneity, in the majority of sectors (and on average across sectors) import prices are positively related to RER movements, as expected.

Columns 4-6 of Table 5 report the first-stage estimates including the two external instruments — the predicted change in import price, $\triangle \widehat{\widehat{w}}_{i n t}^{i m p}$ from (20), and the predicted wage change instrument, $\triangle z_{i t}$ from $(22)$ - and one internal instrument, the lagged level of capital from $t-2$. The coefficient estimates broadly conform to our expectations. In particular, the predicted import price change is significantly negatively related to the change in the material quantity aggregate and the predicted wage change is significantly negatively related to the change in employment. In the latter case, the predicted wage change is also negatively related to the materials and capital changes. The instruments are somewhat stronger than in the internal-instruments-only model in Columns 1-3, but both the SW F-statistic for materials and labor and the KP Wald statistic continue to warrant concern about the weakness of the instruments.

Our preferred specification combines the three internal instruments from $t-2$ and the external instruments. The corresponding first stage is reported in Columns 7-9 of Table 5. The coefficient estimates are similar to those in the other columns but the strength of the instrument set has improved. The SW F-statistic is above the rule-of-thumb level of 10 for labor and capital and the KP Wald statistic, while still somewhat low at 3.363, is noticeably larger than in the other columns. The concern about the weakness of instruments remains, but it has been mitigated by the inclusion of the external instruments.

Table 6 presents the second-stage estimates for the three instrument sets in Table 5 . In the first two columns, the coefficients on materials and labor are imprecisely estimated and change markedly across columns, as one might expect given the weakness of the instruments in these specifications. In our preferred specification in Column 3, by contrast, the materials and labor coefficients are more precisely estimated and are of plausible magnitudes, .38 and .40 respectively. The labor coefficient is substantially larger than, and the materials coefficient very similar to, the corresponding FD estimates in Table 4, Panel B, Columns 3-4. The difference in the labor coefficient is consistent with the presence of an output-quality bias discussed above: if producing 
higher-quality output requires more labor, then we would expect a positive correlation between $\triangle \ell_{i t}$ and $\triangle q_{i t}^{y}$ in (16), generating a negative bias in OLS and FD estimates of $\beta_{\ell}$, which our approach would correct. ${ }^{44}$

As previewed above, the capital coefficient is implausibly low in this specification. The point estimate is in fact negative, although the confidence interval allows for positive values of roughly the magnitude of the OLS estimate in Columns 3-4 of Table 4, Panel A. We believe that the reason for the erratic estimate is that most of the genuine variation in capital stock is between rather than within firms, and that once first-differencing removes the firm effect, much of the remaining within-firm variation is due to measurement error. In Step 2 below, using the levels equation, we will use the variation between firms to arrive at a more plausible point estimate for the capital coefficient.

Given that the SW F-statistic for materials and the KP Wald statistic are still somewhat low in our preferred specification, we explore the robustness of the estimates in two ways. First, we report weak-instrument-robust confidence intervals. The econometric literature has not reached consensus on the best method for estimating these intervals, especially in the non-homoskedastic case. Here we follow the approach of Andrews (2016, 2018), which uses a statistic based on a linear combination (LC) of the K statistic of Kleibergen (2005) and the S statistic of Stock and Wright (2000). ${ }^{45}$ We treat $\beta_{k}$ as a nuisance parameter (without assuming it is strongly identified); the confidence intervals for $\beta_{m}$ and $\beta_{\ell}$ are calculated using a projection method due to Chaudhuri and Zivot (2011). These intervals are reported in Column 3 of Table 5. The intervals are centered at the reported point estimates and allow us to reject the nulls that $\beta_{m}=0$ and $\beta_{\ell}=0$ comfortably at the $95 \%$ level. Second, to further probe robustness, we estimate the Column 3 specification using limited-information maximum likelihood (LIML), which has been found to be more robust to weak instruments than IV (Stock et al., 2002; Angrist and Pischke, 2009). The Andrews LC robust confidence intervals, reported in Column 4, are somewhat larger, but the coefficient estimates are nearly identical to those in Column 3, which is reassuring. While it would be preferable to have stronger instruments, we interpret these results as indicating that our first-step IV estimates of

\footnotetext{
${ }^{44}$ Another possibility is that measurement error in labor generated attenuation bias in the FD estimate, which our procedure removes.

${ }^{45}$ In practice, the confidence region is found by using this linear combination (referred to as the LC statistic) to test the null hypothesis at each point on a grid roughly spanning the parameter space; the confidence region is then the set of points at which the null cannot be rejected. The LC statistic provides more powerful tests than the K or S statistics alone under some circumstances. Conveniently, this procedure is implemented in Stata by the twostepweakiv command (Sun, 2018).
} 
$\beta_{m}$ and $\beta_{\ell}$ are robust to weak-instrument concerns.

\subsection{Levels (Step 2) Results}

We now turn to the second step of our TSIV procedure. We consider the levels equation, (24), where we plug in the difference equation (Step 1) estimates, $\widehat{\beta}_{m}$ and $\widehat{\beta}_{\ell}$, on the left-hand side.

Panel A of Table 7 reports the first stage of the IV procedure for this step. Our preferred specification, using $\triangle k_{i t-1}$ as the instrument for $k_{i t}$ appears in Column 1. To check robustness, we also report results using $\triangle k_{i t-2}$ as the instrument in Column 2. In neither case is there a weakinstrument concern: the Kleibergen-Papp Wald statistic is above 36 in both cases. ${ }^{46}$ Although the R-squared of the first-stage regression is low, the first-stage coefficient is .67 in both columns and highly significant.

Panel B of Table 7 reports the corresponding second stage. Columns 1 and 2 correspond to the same Columns in Panel A, with $\triangle k_{i t-1}$ and $\triangle k_{i t-2}$ as instruments, respectively. For comparison purposes, Column 3 reports the OLS estimate, without instrumenting $k_{i t}$. Below each estimate, we report the uncorrected standard errors in parentheses and the corrected standard errors in brackets. As noted in Subsection 2.4.2, the uncorrected standard errors are appropriate in the special case that the instrument is uncorrelated with $\widetilde{m}_{i t}^{S V}$ and $\ell_{i t}$. Otherwise, the corrected standard errors are the appropriate ones. It is important to acknowledge that with the corrected standard errors, the confidence intervals in both columns are wide and we cannot reject the null that $\beta_{k}=0$ at conventional levels.

Despite the large standard errors following the correction, we consider these results to be reassuring. The point estimate in our preferred (Column 1) specification, .20, is plausible, and (together with the first-step estimates of $\widehat{\beta}_{m}$ and $\widehat{\beta}_{\ell}, .38$ and .40 ) indicates that that returns to scale are very nearly constant, as is generally expected (Bartelsman and Doms, 2000). ${ }^{47}$ While one would of course prefer to have a more precise estimate of $\beta_{k}$, we have more confidence in the estimate than in the close-to-zero estimates from the naive first-differences models in Columns 3-4 of Panels A and B of Table 4 or the negative estimates from the Step 1 difference equation in Table 6.

\footnotetext{
${ }^{46}$ The Kleibergen-Papp Wald statistic and the Sanderson-Windmeijer F statistic coincide in cases with a single endogenous covariate.

${ }^{47}$ If we instead use the Column 2 estimate of .29 , the materials, labor and capital coefficients sum to 1.07 but this is not statistically significantly different from 1 .
} 
It is notable that our TSIV estimates of $.38, .40$, and .20 for $\beta_{m}, \beta_{\ell}$, and $\beta_{k}$ are, in the end, quite similar to (and not statistically different from) the naive OLS results using our input and output quantity aggregates in Columns 1-2 of Table 4, Panel B. One might reasonably ask what has been gained by going through our new procedure. We note that it was by no means obvious at the beginning that the TSIV estimates would be so similar to the OLS-in-levels estimates. The labor and capital coefficients drop after first-differencing to remove the firm effect, and then rise again with our procedure. Although many explanations are possible, this pattern is consistent with the hypothesis that there are two offsetting biases in the naive OLS results: a transmission bias due to the firm effect, $\eta_{i}$, and a quality bias due to greater use of labor for higher-quality outputs. While these two biases may offset in the current setting, they may not always, and it is potentially quite useful to have a method that can address both. Comparing to the naive OLS estimates using sales and purchases in Columns 1-2 of Table 4, the fact that the materials coefficient is significantly smaller when using the quantity aggregates, both in the OLS estimates in Columns 5-6 of Table 4 and our TSIV estimates, underlines the importance of having access to quantity information on inputs and outputs.

\section{Robustness}

\subsection{Alternative Aggregators}

Our within-firm CES assumptions are convenient for showing theoretically how quality and variety differences may bias estimates of output elasticities, but they are admittedly restrictive. It is natural to ask whether our particular functional-form assumptions are driving our results. It turns out that the empirical patterns are robust to using other common aggregators to aggregate from the firm-product to the firm level: a Tornqvist index, a Paasche index, and a Laspeyres index. Appendix Tables A4-A6 report estimates analogous to Tables 5-7 using these alternative aggregators and the combination of external and internal instruments. The results are qualitatively similar. The point estimates display small differences from our baseline estimates — the Tornqvist materials coefficient is larger, the Paasche labor coefficient is smaller, and the Laspeyres capital coefficient is smaller — but these differences are not statistically significant. Using the weak-instrument-robust confidence intervals, we see that the Laspeyres materials coefficient is not significantly different from zero at the $95 \%$ level, but it is significant at the $90 \%$ level. Overall, 
these results suggest that the empirical patterns are not particularly sensitive to the functional form of the aggregator that we use.

\subsection{Adding Predicted Export Price Index}

Changes in real exchange rates in export destinations may affect export prices and how much firms sell in those destinations, in addition to the prices of imports. If export destinations are correlated with import origins at the market level and individual-firm level in Colombia, that could generate a correlation between our predicted import price index, $\triangle \widehat{\bar{w}}_{i t}^{i m p}$, and the error term, $\triangle u_{i t}$. To address this concern, we construct a predicted export price index, $\triangle \widehat{\bar{w}}_{i t}^{e x p}$, analogous to the predicted import price index, and include it as a covariate. We follow the same steps as for constructing the predicted import price index: we generate leave-one-out estimates of export price changes and then average these using the composition of firms' export baskets. In Appendix Tables A7-A8, this predicted export price index is included as an additional covariate. The results are very similar to our baseline estimates. The $95 \%$ weak-instrument-robust confidence interval for the materials coefficient includes zero, but we can still reject the null that $\beta_{m}=0$ at $90 \%$ confidence. The basic patterns are robust to including the export price control.

\subsection{Alternative Samples}

As discussed in Subsection 3.4, in choosing which subsectors to focus on we have faced a trade-off between increasing sample size and reducing cross-firm heterogeneity. To explore this trade-off further, we present estimates for two additional samples. In the first, we include only producers of plastic products (ISIC rev. 2 code 356 ). In the second, we add another subsector that also, arguably, uses relatively homogeneous inputs, produces differentiated outputs, and imports a substantial share of inputs: producers of glass products (ISIC rev. 2 code 362). ${ }^{48}$ Appendix Tables A9-A11 report the estimates for the alternative samples. Unsurprisingly, the precision of the estimates is increasing in sample size. The weak-instrument statistics signal greater reason for concern in the plastics-only sample, and somewhat less reason in the combined rubber, plastics, and glass sample. But overall, the patterns are similar to the sample with rubber and plastics producers in our baseline estimates.

\footnotetext{
${ }^{48}$ Recall that Appendix Tables A1-A2 report summary statistics for glass products.
} 


\section{Comparison to Output Elasticities from Other Methods}

This section compares our output-elasticity estimates to those of other commonly used methods applied in our sample, using log sales and log expenditures rather than our Sato-Vartia quantity indexes. As noted above, our approach is perhaps closest in spirit to System GMM (Arellano and Bover, 1995; Blundell and Bond, 1998, 2000). The standard System GMM set-up has a CobbDouglas production function and a firm effect, as we do, but it assumes the ex ante component of productivity (here $\omega_{i t}$ ) follows an $\mathrm{AR}(1)$ process. After quasi-differencing to remove the serial correlation in the error, the main estimating equation contains a lagged dependent variable as well as lags of covariates. Difference and levels equations are then estimated simultaneously.

Table 8 presents the results from applying standard System GMM in our baseline sample. We include time fixed effects and use the "two-step" procedure described in Roodman (2009), using the initial weighting matrix defined in Doornik et al. (2012) and implementing the Windmeijer (2005) finite-sample correction for the resulting covariance matrix. ${ }^{49}$ The coefficients on contemporaneous log expenditures, log labor, and log capital are estimates of the Cobb-Douglas output elasticities, corresponding to our $\beta_{m}, \beta_{\ell}$, and $\beta_{k} .{ }^{50}$ The columns differ in the number of lags of the covariates in levels that are included in the difference equation, with lags just from $t-2$ in Column 1, from $t-2$ and $t-3$ in Column 2, and from all available periods starting from $t-2$ in Column 3. The instruments are included "GMM-style," effectively interacted with year dummies (Holtz-Eakin et al., 1988; Roodman, 2009). In the corresponding levels equations, we include the first lags of the first-differenced covariates as instruments. ${ }^{51}$ To gauge the strength of the instruments, we follow Bazzi and Clemens (2013) and Kraay (2015) in reporting weak-instrument diagnostics separately for the differences and levels equations in Appendix Table A12. In the differences equation, the number of instruments the rises quickly (given that lags from different years are considered different instruments), from 56 in Column 1 to 420 in Column 3. The set of instruments appears to be weak, with the Kleibergen-Paap Wald test statistic below 2 and the Sanderson-Windmeijer F-statistics below 2 for contemporaneous labor and capital, and below 3

\footnotetext{
${ }^{49}$ In particular, we use the Stata xtabond2 command of Roodman (2009) with options h(2), twostep, and robust. Following Roodman's replication of Blundell and Bond (1998), we include time fixed effects as instruments only in the levels equation, since they are asymptotically redundant in the difference equation.

${ }^{50}$ The model implies additional restrictions on the relationship between the coefficients on the contemporaneous and lagged terms, which we do not test here.

${ }^{51}$ Further lags of differences in the levels equation are redundant (Arellano and Bover, 1995; Blundell and Bond, 2000).
} 
for contemporaneous materials expenditures. ${ }^{52}$ That said, it is worth noting that the resulting coefficient estimates are not very far from our baseline estimates: focusing on the specification in Column 3 (using all available instruments), the point estimate of .48 for materials is larger than our $\widehat{\beta}_{m}^{T S I V}$ of .38, the point estimate of .26 for labor is smaller than our $\widehat{\beta}_{l}^{T S I V}$ of .40, but these differences are not statistically significant. The point estimate for capital of .03 is significantly smaller than our $\widehat{\beta}_{k}^{T S I V}$ of $.20 .^{53}$

Table 9 reports estimates from four leading proxy-variable methods: those of Olley and Pakes (1996) (OP), Levinsohn and Petrin (2003) (LP), Wooldridge (2009) (using materials as the proxy), and Gandhi, Navarro and Rivers (2020) (GNR). ${ }^{54}$ The method of Ackerberg, Caves and Frazer (2015) (ACF) is also commonly used, but the authors recommend that it only be used with valueadded production functions, not gross output functions, and hence their coefficient estimates are not directly comparable to ours. For OP, LP and Wooldridge in Columns 1-3, the point estimates for materials are consistently higher than our baseline estimate, and fall outside our weak-instrument-robust confidence interval. ${ }^{55}$ The point estimate for labor is consistently lower than our baseline estimate, although not significantly so. The GNR estimate of the materials coefficient in Column 4 is very similar to ours, and the labor coefficient is somewhat larger although not significantly so. ${ }^{56}$ Overall, although the differences in estimates are generally not statistically significant, it is worth emphasizing that they will be of consequence when the point estimates are used to estimate markups or productivity, as we will see in the next section.

\section{Measures of Productivity}

Our main objective in this paper is to estimate the output elasticities consistently, without price, quality, or variety biases, and we have argued that our method achieves this goal. But once we

\footnotetext{
${ }^{52}$ The Hansen test of over-identifying restrictions is appropriate in the non-homoskedastic case and does not reject the hypothesis that the instruments are jointly valid. But it should be interpreted with caution, as it is weakened by the presence of many instruments (Roodman, 2009).

${ }^{53}$ In Appendix Table A13, we report the results of System GMM estimation with our quantity aggregates in place of revenues and expenditures. The results are broadly similar, with slighly lower estimates of the materials and labor elasticities, and somewhat higher estimate of the capital elasticity.

${ }^{54}$ For OP, LP and Wooldridge, we use the Stata command prodest (Rovigatti and Mollisi, 2018); for GNR, we have coded the estimation ourselves. For all specifications we obtain standard errors by using a bootstrap with 50 replications.

${ }^{55}$ Note that for OP a large number of firms report zero investment in capital for some years and are dropped from the estimation.

${ }^{56}$ In implementing GNR, given the Cobb-Douglas structure of the the production function, we use a polynomial of degree zero for the materials expenditure elasticity, a polynomial of degree one in capital and labor for the integration constant, and a polynomial of degree three for the $\operatorname{AR}(1)$ process of $\omega_{i t}$ (i.e. $\omega_{i t}=\sum_{a=1}^{3} \delta_{a} \omega_{i t-1}^{a}$ ).
} 
have the elasticity estimates in hand, it is natural to ask whether we can use them to construct a measure of productivity. In this section, we define and discuss productivity measures using our estimates (Subsection 7.1) and compare our preferred measure to other common methods in predicting export performance (Subsection 7.2).

\subsection{Definitions}

Our output-elasticity estimates can be used to construct two different TFP measures, depending on whether we use our Sato-Vartia quantity indexes or revenues and expenditures. We refer to these two measures as $T F P Q^{\prime}$ and $T F P R^{\prime}$. Neither measure captures only technical efficiency, but their shortcomings differ, in ways that are useful to examine. In this subsection we focus on changes in productivity rather than levels, because in changes we can avoid taking a stand on the firm-specific normalizations, $\widetilde{y}_{i 0}$ and $\widetilde{m}_{i 0}$.

To define $\triangle T F P Q^{\prime}$, we use the observable Sato-Vartia quantity indexes, $\widetilde{y}_{i t}^{S V}$ and $\widetilde{m}_{i t}^{S V}:{ }^{57}$

$$
\triangle T F P Q_{i t}^{\prime}=\triangle \widetilde{y}_{i t}^{S V}-\widehat{\beta}_{m} \triangle \widetilde{m}_{i t}^{S V}-\widehat{\beta}_{k} \triangle k_{i t}-\widehat{\beta}_{\ell} \triangle \ell_{i t}
$$

In our model, technical efficiency is represented by $\triangle \omega_{i t}+\triangle \epsilon_{i t}+\triangle \xi_{t}{ }^{58}$ But referring to (16), we see that:

$$
\operatorname{plim}_{I \rightarrow \infty} \triangle T F P Q_{i t}^{\prime}=\triangle \xi_{t}+\triangle \omega_{i t}+\triangle \epsilon_{i t}+\left(\beta_{m} \triangle v_{i t}^{m}-\triangle v_{i t}^{y}\right)+\left(\beta_{m} \triangle q_{i t}^{m}-\triangle q_{i t}^{y}\right)
$$

That is, changes in quality and variety of both outputs and inputs are captured in $\triangle T F P Q^{\prime}$. If we can can be confident that output and input quality and variety are roughly constant over time - as for instance for single-product, single-input firms in homogeneous-good industries — then $\triangle T F P Q^{\prime}$ is a consistent estimator for technical efficiency. But to the extent that a firm increases output quality or variety, $\triangle T F P Q^{\prime}$ will understate increases in technical efficiency, and to the extent that it increases input quality or variety, it will overstate them. This may explain, for instance, why the Egyptian rug producers randomly allocated an initial export contract in Atkin et al. (2017, 2019) saw increases in output quality, profitability, and productivity measured under

\footnotetext{
${ }^{57}$ Note that in the case of single-product, single-input firms, $\widetilde{y}_{i t}^{S V}$ and $\widetilde{m}_{i t}^{S V}$ reduce to the physical quantity of the single output and input.

${ }^{58}$ There is some difference in practice in whether to include the year effect, $\triangle \xi_{t}$, in the definition of TFP. Here we do, but note that it can be removed by deviating from year means.
} 
laboratory conditions, but a decrease in physical-quantity-based TFP.

To define $\triangle T F P R^{\prime}$, we use firm revenues and expenditures, $r_{i t}$ and $e_{i t}$, in place of the output and input quantity indexes, $\widetilde{y}_{i t}^{S V}$ and $\widetilde{m}_{i t}^{S V}$ :

$$
\triangle T F P R_{i t}^{\prime}=\triangle r_{i t}-\widehat{\beta}_{m} \triangle e_{i t}-\widehat{\beta}_{k} \triangle k_{i t}-\widehat{\beta}_{\ell} \triangle \ell_{i t}
$$

Given $r_{i t}=\widetilde{y}_{i t}+\widetilde{p}_{i t}, e_{i t}=\widetilde{m}_{i t}+\widetilde{w}_{i t}$, and the relationships in (13)-(14), it follows that:

$$
\operatorname{plim}_{I \rightarrow \infty} \triangle T F P R_{i t}^{\prime}=\triangle \xi_{t}+\triangle \omega_{i t}+\triangle \epsilon_{i t}+\triangle \widetilde{p}_{i t}-\beta_{m} \triangle \widetilde{w}_{i t}
$$

Relative to $\triangle T F P Q^{\prime}, \triangle T F P R^{\prime}$ has the advantage that changes in quality and variety are absorbed in the revenues and expenditure terms. But it has the disadvantage that it captures pure price changes, reflected in the price index changes, $\triangle \widetilde{p}_{i t}$ and $\triangle \widetilde{w}_{i t}$. Abstracting from variety changes, if there are no changes in quality-adjusted prices (e.g. if both quality and prices are constant, or if price changes fully reflect quality changes and not other factors), then $\triangle \widetilde{p}_{i t}=\triangle \widetilde{w}_{i t}=0$ and $\triangle T F P R^{\prime}$ reflects changes in technical efficiency only. On the other hand, if quality-adjusted prices of outputs or inputs change, they show up in $\triangle T F P R^{\prime}$.

Whether $\triangle T F P Q^{\prime}$ or $\triangle T F P R^{\prime}$ is the more appropriate measure thus depends to some extent on the setting and analytical objective, with $\triangle T F P Q^{\prime}$ better suited in homogeneous industries and $\triangle T F P R^{\prime}$ arguably more informative in industries with greater vertical differentiation and/or output and input specialization. In the case of the rubber and plastics industries in Colombia, in which quality differences are likely to be important, we believe that $\triangle T F P R^{\prime}$ is the more appropriate measure. At the same time, it is important to remain aware that it may reflect price changes as well as changes in technical efficiency.

\subsection{Comparison with Other TFP Measures}

How does our preferred measure of productivity compare to other standard measures? As a first illustration, Appendix Table A14 reports pairwise correlation coefficients between the levels of TFP calculated using different methods. ${ }^{59}$ To the methods in Tables 8, 9 and A13 mentioned above, we add estimates from the Ackerberg et al. (2015) method, using a value-added production

\footnotetext{
${ }^{59}$ In levels, we define:

$T F P R^{\prime}=r_{i t}-\widehat{\beta}_{m} e_{i t}-\widehat{\beta}_{k} k_{i t}-\widehat{\beta}_{\ell} \ell_{i t}$
} 
function, and from the OLS estimation with quantity aggregates from Table 4. Overall, the different measures are reasonably highly correlated with one another, an observation that has been made for instance by Van Biesebroeck (2008) and Eslava et al. (2009) for different sets of methods, but the correlations are far from perfect. Our measure is most highly correlated with the System GMM estimates, LP and Wooldridge, and least correlated with OP and ACF.

One way to begin to evaluate the performance of different estimators is to examine how well they predict outcomes that one can be fairly confident are related to firms' technical efficiency. Here, as a first step, we relate estimated changes in productivity to future changes in export performance. Although there is little agreement in the literature about whether exporting itself increases productivity, there is a broader consensus that productivity increases are likely to predict future expansions of exports (Bernard and Jensen, 1999; Alvarez and López, 2005; Costantini and Melitz, 2008; Aw et al., 2011). Relating productivity to future export growth also avoids concerns about how changes in markups or product composition due to exporting might affect contemporaneous productivity estimates.

Table 10 reports correlations between changes in the various productivity measures from period $t-s$ to $t$ and changes in the inverse hyperbolic sine of the value of exports from $t$ to $t+s$, where $s \in\{1,2,3\}$. We standardize all measures so that they have standard deviation 1 (pooling years) and we include year effects. ${ }^{60}$ In all specifications, the $R^{2}$ is quite small, and for the single-period differences $(s=1)$, none of the TFP measures are significant predictors of future exports. But for longer differences, we find that all of the productivity measures are significant predictors of future export growth. Given that the measures have been standardized, the magnitude of the coefficients can be interpreted as an indicator of the strength of the relationship, and we see that our measure is a stronger predictor of future export growth than the other measures we have considered. Although the explanatory power of all of the measures is quite low, our measure has the largest $R^{2}$ among the set. These results are by no means definitive, but we view them as suggestive that our measure represents a modest improvement in measuring technical efficiency in our setting.

using the notation from above, where $r_{i t}$ and $e_{i t}$ is material expenditures. For the other methods, TFP is defined analogously, using log revenues.

${ }^{60}$ Note that the longer the differences we use, the fewer observations we are able to include in the sample, since we lose observations either at the beginning or the end of the spell in the sample for each firm. 


\section{Conclusion}

This paper has developed a method for estimating production-function parameters that can be applied in differentiated-product industries. We believe that three contributions stand out. First, we have highlighted the pitfalls of using physical quantities to estimate output elasticities or TFP in industries where quality and variety vary by firm and over time. Using within-firm CES aggregators for outputs and material inputs, we have shown theoretically how standard estimates of output elasticities are likely to be biased by quality and variety differences. Second, we have used external drivers of input prices as instruments to estimate the elasticities of output with respect to materials and labor. The idea of using external instruments is not new (Griliches and Mairesse, 1998), but previous authors have not had access to the combination of datasets and naturally occurring variation that we have been able to take advantage of here. Third, we have developed an approach to improving estimates of the output elasticity with respect to capital. It is well known that models in first-differences yield unsatisfactory estimates of the capital coefficient, and our first-step model is not an exception. In the spirit of System GMM, we have added a levels equation, using a lagged difference as an instrument. Our two-step IV (TSIV) approach has the advantage that the estimates of the materials and labor coefficients are robust to misspecification of the second step, which requires stronger assumptions. Our method addresses the quality and variety biases we have identified, in addition to transmission bias, and measures of productivity changes constructed using our estimates do well in comparison to other standard measures in predicting future export growth at the firm level.

Two important questions remain open. The first is what to do if one does not have the combination of rich data and naturally occurring variation that we have in our setting. Data on physical quantities of both inputs and outputs are becoming increasingly available, including in Spain (Doraszelski and Jaumandreu, 2013, 2018), Portugal (Bastos et al., 2018), the United States (Roberts and Supina, 1996; Foster et al., 2008; Atalay, 2014), Chile (Garcia-Marin and Voigtländer, 2019), Ecuador (Bas and Paunov, 2020), Bangladesh (Cajal Grossi et al., 2019), Japan in the Meiji period (Braguinsky et al., 2015), China (Brandt et al., forthcoming) and India (Gupta, 2020). But it may be difficult to find credible external instruments and internal instruments may be weak. One potential way forward would be to construct proxies for the quality and variety terms that appear in estimating equations such as (14)-(15) above. The approach of De Loecker et al. (2016) of including a flexible function of output price and market share on 
the right-hand-side is a promising step in this direction. One could also consider constructing explicit measures of quality, as for instance Khandelwal et al. (2013) do for output quality; such a strategy would require imposing more structure on consumer demand than we have been willing to do here, but may be warranted in some circumstances. To proxy for variety, one could include the observable components of the variety terms derived above and allow for firm-specific coefficients on them. ${ }^{61}$ It is also worth noting that in our setting, OLS in levels using the firm-level output and input quantity aggregates yield estimates very similar to our TSIV procedure; the biases due to unobserved quality and variety changes and the biases deriving from correlations between input choices and time-invariant firm effects appear to offset. More research is required to determine if this generalizes to other contexts; if it does, such OLS estimates may prove to be very useful measures in settings where quantity data are available but credible external instruments are not.

The second big open question is how to arrive at a measure of changes in technical efficiency that excludes both pure price changes and changes in unobserved quality and variety. We believe that our method yields an improved set of output elasticity estimates. But even with these improved estimates, neither quantity-based TFP nor revenue-based TFP is an ideal measure of technical efficiency, as discussed above in Section 7. The proxy strategies mentioned in the previous paragraph represent one way forward, as they would provide direct measures of the quality and variety terms that could be used to correct quantity-based TFP. Another approach would be to use revenue-based TFP but to estimate markups explicitly in order to purge them from the productivity estimate. Garcia-Marin and Voigtländer (2019) and Blum et al. (2018) have recently pursued a strategy in this spirit, using the method of De Loecker et al. (2016) to estimate markups. We believe that our method for estimating output elasticities will help to improve estimates of markups in the approaches of De Loecker and Warzynski (2012) and De Loecker et al. (2016) and hence could help to improve revenue-based TFP measures along these lines.

\section{References}

Ackerberg, Daniel A., Kevin Caves, and Garth Frazer, "Identification Properties of Recent Product Function Estimators," Econometrica, 2015, 83 (6), 2411-2451.

\footnotetext{
${ }^{61}$ Note that the variety terms in (14)-(15) depend on observables (the $\chi$ terms) and time-invariant constants (the elasticities of substitution, $\sigma_{i}^{y}$ and $\left.\sigma_{i}^{m}\right)$.
} 
Ackerberg, Daniel, C. Lanier Benkard, Steven Berry, and Ariel Pakes, "Econometric Tools for Analyzing Market Outcomes," in James Heckman and Edward Leamer, eds., Handbook of Econometrics, vol. 6A, Amsterdam: Elsevier, 2007, chapter 63, pp. 4172-4276.

Alvarez, Roberto and Ricardo A. López, "Exporting and Performance: Evidence from Chilean Plants," Canadian Journal of Economics, 2005, 38 (4).

Anderson, T. W. and Cheng Hsiao, "Formulation and Estimation of Dynamic Models Using Panel Data," Journal of Econometrics, 1982, 18 (1), 47 - 82.

Andrews, Isaiah, "Conditional Linear Combination Tests for Weakly Identified Models," Econometrica, 2016, 84 (6), 2155-2182.

_ , "Valid Two-Step Identification-Robust Confidence Sets for GMM," Review of Economics and Statistics, 2018, 100 (2), 337-348.

_ , James H Stock, and Liyang Sun, "Weak Instruments in Instrumental Variables Regression: Theory and Practice," Annual Review of Economics, 2019, 11, 727-753.

Angrist, Joshua D. and Jorn-Steffen Pischke, Mostly Harmless Econometrics: An Empiricist's Companion, Princeton University Press, 2009.

Arellano, Manuel and Olympia Bover, "Another Look at the Instrumental Variable Estimation of Error-Components Models," Journal of Econometrics, 1995, 68 (1), 29-51.

_ and Stephen Bond, "Some Tests of Specification for Panel Data: Monte Carlo Evidence and an Application to Employment Equations," Review of Economic Studies, 1991, 58 (2), 277 - 297.

Atalay, Enghin, "Materials Prices and Productivity," Journal of the European Economic Association, 2014, 12 (3), 575-611.

Atkin, David, Amit K. Khandelwal, and Adam Osman, "Exporting and Firm Performance: Evidence from a Randomized Trial," Quarterly Journal of Economics, 2017, 132 (2), 551-615.

$\ldots, \ldots$, and _ , "Measuring Productivity: Lessons from Tailored Surveys and Productivity Benchmarking," AEA Papers and Proceedings, 2019, 109, 444-49.

Aw, Bee Yan, Mark J. Roberts, and Daniel Xu, "R\&D Investment, Exporting and Productivity Dynamics," American Economic Review, 2011, 101 (4), 1312-1344.

Balat, Jorge, Irene Brambilla, and Yuya Sasaki, "Heterogeneous Firms, Skilled-Labor Productivity and the Destination of Exports," 2018. Unpub. paper, UT Austin.

Bartelsman, Eric J. and Mark Doms, "Understanding Productivity: Lessons from Longitudinal Microdata," Journal of Economic Literature, September 2000, 38 (3), 569-594.

Bas, Maria and Caroline Paunov, "The Role of Productivity and Markups in Determining Trade Liberalization's Impact on Firm Product Scope and Innovation," 2020. Unpub. paper.

Bastos, Paulo, Joana Silva, and Eric Verhoogen, "Export Destinations and Input Prices: Evidence from Portugal," American Economic Review, 2018, 108 (2), 353-392.

Baum, Christopher F., Mark E. Schaffer, and Steven Stillman, "Enhanced Routines for Instrumental Variables/Generalized Method of Moments Estimation and Testing," Stata Journal, 2007, 7 (4), 465-506.

Bazzi, Samuel and Michael A Clemens, "Blunt instruments: Avoiding common pitfalls in identifying the causes of economic growth," American Economic Journal: Macroeconomics, 2013, 5 (2), 152-86.

Bell, Linda, "The Impact of Minimum Wages in Mexico and Colombia," Journal of Labor Economics, 1997, 15, s102-s123.

Bernard, Andrew B. and J. Bradford Jensen, "Exceptional Exporter Performance: Cause, Effect, or Both?," Journal of International Economics, Feb. 1999, 47, 1-25.

_ , Stephen J. Redding, and Peter K. Schott, "Multi-Product Firms and Trade Liberalization," Quarterly Journal of Economics, 2011, 126 (3), 1271-1318.

Berry, Steven, Amit Gandhi, and Philip Haile, "Connected Substitutes and Invertibility of Demand," Econometrica, 2013, 81 (5), 2087-2111.

Blum, Bernardo S, Sebastian Claro, Ignatius Horstmann, and David A Rivers, "The ABCs of Firm Heterogeneity: The Effects of Demand and Cost Differences on Exporting," 2018. Unpub. paper, University of Toronto. 
Blundell, Richard and Stephen Bond, "Initial Conditions and Moment Restrictions in Dynamic Panel Data Models," Journal of Econometrics, 1998, 87 (1), 115-143.

_ and _ , "GMM Estimation with Persistent Panel Data: An Application to Production Functions," Econometric Reviews, 2000, 19 (3), 321-340.

Bond, Stephen R., "Dynamic Panel Data Models: A Guide to Micro Data Methods and Practice," Portuguese Economic Journal, 2002, 1 (2), 141 - 162.

Bond, Steve, Arshia Hashemi, Greg Kaplan, and Piotr Zoch, "Some Unpleasant Markup Arithmetic: Production Function Elasticities and their Estimation from Production Data," 2020. NBER working paper no. 27002.

Braguinsky, Serguey, Atsushi Ohyama, Tetsuji Okazaki, and Chad Syverson, "Acquisitions, productivity, and profitability: evidence from the Japanese cotton spinning industry," American Economic Review, 2015, 105 (7), 2086-2119.

Brandt, Loren, Feitao Jiang, Yao Luo, and Yingjun Su, "Ownership and Productivity in Vertically Integrated Firms: Evidence from the Chinese Steel Industry," 2018. Unpub. paper, University of Toronto.

$\ldots, \ldots, \ldots$, and _, "Ownership and Productivity in Vertically Integrated Firms: Evidence from the Chinese Steel Industry," Review of Economics and Statistics, forthcoming.

Bun, Maurice J. G. and Frank Windmeijer, "The Weak Instrument Problem of the System GMM Estimator in Dynamic Panel Data Models," Econometrics Journal, 2010, 13 (1), 95-126.

_ and Vasilis Sarafidis, "Dynamic Panel Data Models," Oxford Handbook of Panel Data, 2015, pp. 76110.

Cajal Grossi, Julia, Rocco Macchiavello, and Guillermo Noguera, "International Buyers' Sourcing and Suppliers' Markups in Bangladeshi Garments," 2019. CEPR discussion paper no. 13482.

Campa, Jose Manuel and Linda S. Goldberg, "Exchange Rate Pass-Through into Import Prices," Review of Economics and Statistics, 2005, 87 (4), 679-690.

Card, David, "Using Regional Variation in Wages to Measure the Effects of the Federal Minimum Wage," Industrial and Labor Relations Review, 1992, 46 (1), pp. 22-37.

Cengiz, Doruk, Arindrajit Dube, Attila Lindner, and Ben Zipperer, "The Effect of Minimum Wages on Low-Wage Jobs*," The Quarterly Journal of Economics, 05 2019, 134 (3), 1405-1454.

Chamberlain, Gary, "Multivariate Regression Models for Panel Data," Journal of Econometrics, 1982, $18,5-46$.

Chaudhuri, Saraswata and Eric Zivot, "A New Method of Projection-Based Inference in GMM with Weakly Identified Nuisance Parameters," Journal of Econometrics, 2011, 164 (2), 239-251.

Collard-Wexler, Allan and Jan De Loecker, "Production Function Estimation with Measurement Error in Inputs," 2016. NBER working paper no. 22437.

Costantini, James A. and Marc J. Melitz, "The Dynamics of Firm-Level Adjustment to Trade Liberalization," in Elhanan Helpman, Dalia Marin, and Thierry Verdier, eds., The Organization of Firms in a Global Economy, Cambridge MA: Harvard University Press, 2008, pp. 107-141.

Cragg, John G. and Stephen G. Donald, "Testing Identifiability and Specification in Instrumental Variable Models," Econometric Theory, 1993, 9 (2), 222-240.

De Loecker, Jan, "Product Differentiation, Multi-product Firms and Estimating the Impact of Trade Liberalization on Productivity," Econometrica, 2011, 79 (5).

- and Frederic Warzynski, "Markups and Firm-level Export Status," American Economic Review, 2012, 102 (6), 2437-2471.

- and Pinelopi Koujianou Goldberg, "Firm Performance in a Global Market," Annual Review of Economics, 2014, 6 (1), 201-227.

_ , Pinelopi K. Goldberg, Amit K. Khandelwal, and Nina Pavcnik, "Prices, Markups and Trade Reform," Econometrica, 2016, 84 (2), 445-510.

Dhyne, Emmanuel, Amil Petrin, Valerie Smeets, and Frederic Warzynski, "Multi Product Firms, Import Competition, and the Evolution of Firm-Product Technical Efficiencies," 2020. Unpub. paper, Aarhus University.

$\ldots, \ldots, \ldots$, and _ , "Theory for Extending Single-Product Production Function Estimation to Multi- 
Product Settings," 2020. Unpub. paper, Aarhus University.

Doornik, Jurgen A, Manuel Arellano, and Stephen Bond, "Panel Data Estimation Using DPD for Ox," 2012. Available at https://www.doornik.com/download/oxmetrics7/Ox_Packages/dpd.pdf.

Doraszelski, Ulrich and Jordi Jaumandreu, "R\&D and Productivity: Estimating Endogenous Productivity," Review of Economic Studies, 2013, 80 (4), 1338-1383.

_ and _ , "Measuring the Bias of Technological Change," Journal of Political Economy, 2018, 126 (3), 1027-1084.

Eckel, Carsten and J. Peter Neary, "Multi-Product Firms and Flexible Manufacturing in the Global Economy," Review of Economic Studies, Jan 2010, 77, 188-217.

Eslava, Marcela and John C Haltiwanger, "The Life-Cycle Growth of Plants: The Role of Productivity, Demand and Wedges," 2020. NBER working paper no. 27184.

_ , John Haltiwanger, Adriana Kugler, and Maurice Kugler, "The Effects of Structural Reforms on Productivity and Profitability Enhancing Reallocation: Evidence from Colombia," Journal of Development Economics, 2004, 75, 333-371.

$\ldots, \ldots, \ldots$, and _ , "Factor Adjustments After Deregulation: Panel Evidence from Colombian Plants," Review of Economics and Statistics, May 2009, 92 (2), 378-391.

_, _, , , and _, "Trade Reforms and Market Selection: Evidence from Manufacturing Plants in Colombia," Review of Economic Dynamics, 2013, 16, 135-158.

Feenstra, Robert C., "New Product Varieties and the Measurement of International Prices," American Economic Review, 1994, 84 (1), 157 - 177.

Forlani, Emanuele, Ralf Martin, Giordiano Mion, and Mirabelle Muûls, "Unraveling Firms: Demand, Productivity and Markups Heterogeneity," 2016. CEPR Discussion Paper No. 11058.

Foster, Lucia, Cheryl Grim, John Haltiwanger, and Zoltan Wolf, "Firm-level Dispersion in Productivity: Is the Devil in the Details?," American Economic Review, 2016, 106 (5), 95-98.

_ , John Haltiwanger, and Chad Syverson, "Reallocation, Firm Turnover and Efficiency: Selection on Productivity or Profitability?," American Economic Review, 2008, 98 (1), 394-425.

Fox, Jeremy T. and Valérie Smeets, "Does Input Quality Drive Measured Differences in Firm Productivity?," International Economic Review, 2011, 52 (4), 961-989.

Gandhi, Amit, Salvador Navarro, and David Rivers, "On the Identification of Gross Output Production Functions," Journal of Political Economy, 2020, 128 (8), 2973-3016.

Garcia-Marin, Alvaro and Nico Voigtländer, "Exporting and Plant-Level Efficiency Gains: It's in the Measure," Journal of Political Economy, 2019, 127 (4), 1777-1825.

Goldberg, Pinelopi K., Amit Khandelwal, Nina Pavcnik, and Petia Topalova, "Imported Intermediate Inputs and Domestic Product Growth: Evidence from India," Quarterly Journal of Economics, 2010, 125 (4), 1727-1767.

Gong, Binlei and Robin C. Sickles, "Resource Allocation in Multi-divisional Multi-product Firms," 2019. Rice Initiative for the Study of Economics working paper 19-003.

Grieco, Paul L. E. and Ryan C. McDevitt, "Productivity and Quality in Health Care: Evidence from the Dialysis Industry," Review of Economic Studies, 09 2016, 84 (3), 1071-1105.

Grieco, Paul, Shengyu Li, and Hongsong Zhang, "Production Function Estimation with Unobserved Input Price Dispersion," International Economic Review, 2016, 57 (2), 665-690.

Griliches, Zvi and Jacques Mairesse, "Production Functions: The Search for Identification," in Steinar Strom, ed., Econometrics and Economic Theory in the Twentieth Century: The Ragnar Frisch Centennial Symposium, Cambridge University Press, 1998, pp. 169-203.

Gupta, Apoorv, "Firm Heterogeneity, Demand for Quality and Prices: Evidence from India," 2020. Unpub. paper.

Hall, Robert E., "Market Structure and Macroeconomic Fluctuations," Brookings Papers on Economic Activity, 1986, 1986 (2), pp. 285-338.

Hayakawa, Kazuhiko and Meng Qi, "Further Results on the Weak Instruments Problem of the System GMM Estimator in Dynamic Panel Data Models," Oxford Bulletin of Economics and Statistics, 2020, 82 (2), 453-481. 
Hofstetter, Marc, "La Política Monetaria y la Corte Constitucional: El Caso del Salario Mínimo," Revista de Economía Institucional, 2006, 8 (14), 105-124.

Holtz-Eakin, Douglas, Whitney Newey, and Harvey S. Rosen, "Estimating Vector Autoregressions with Panel Data," Econometrica, Nov. 1988, 56 (6), 1371-1395.

Hottman, Colin, Stephen J. Redding, and David E. Weinstein, "Quantifying the Sources of Firm Heterogeneity," Quarterly Journal of Economics, 2016, 131 (3), 1291-1364.

Hsieh, Chang-Tai and Peter J. Klenow, "Misallocation and Manufacturing TFP in China and India," Quarterly Journal of Economics, 2009, 124 (4), pp. 1403-1448.

Jaumandreu, Jordi and Heng Yin, "Comparing Productivity When Products and Inputs Differ in Quality: China Manufacturing Growth 1998-2013," 2018. Unpub. paper.

Katayama, Hajime, Shihua Lu, and James R. Tybout, "Firm-level Productivity Studies: Illusions and a Solution," International Journal of Industrial Organization, May 2009, 27 (3), 403-413.

Khandelwal, Amit K., Peter K. Schott, and Shang-Jin Wei, "Trade Liberalization and Embedded Institutional Reform: Evidence from Chinese Exporters," American Economic Review, 2013, 103 (6), 2169-95.

Kleibergen, Frank, "Testing Parameters in GMM Without Assuming That They Are Identified," Econometrica, 2005, 73 (4), 1103-1123.

- and Richard Paap, "Generalized Reduced Rank Tests using the Singular Value Decomposition," Journal of Econometrics, 2006, 133 (1), 97 - 126.

Klette, Tor Jakob and Zvi Griliches, "The Inconsistency of Common Scale Estimators When Output Prices Are Unobserved and Endogenous," Journal of Applied Econometrics, 1996, 11 (4), 343 - 361.

Kraay, Aart, "Weak Instruments in Growth Regressions: Implications for Recent Cross-Country Evidence on Inequality and Growth," 2015. World Bank Policy Research Working Paper no. 7494.

Kripfganz, Sebastian and Claudia Schwarz, "Estimation of Linear Dynamic Panel Data Models with Time-Invariant Regressors," Journal of Applied Econometrics, 2019, 34 (4), 526-546.

Kugler, Maurice and Eric Verhoogen, "Prices, Plant Size and Product Quality," Review of Economic Studies, January 2012, 79 (1), 307-339.

Levinsohn, James and Amil Petrin, "Estimating Production Functions Using Inputs to Control for Unobservables," Review of Economic Studies, April 2003, 70, 317-341.

Maloney, William F and Jairo Nuñez Mendez, "Measuring the Impact of Minimum Wages: Evidence from Latin America," in James J. Heckman and Carmen Pagés, eds., Law and Employment: Lessons from Latin America and the Caribbean, University of Chicago Press, 2004.

Marschak, Jacob and William H. Andrews, "Random Simultaneous Equations and the Theory of Production," Econometrica, 1944, 12 (3/4), 143-205.

Mayer, Thierry, Marc J Melitz, and Gianmarco IP Ottaviano, "Market Size, Competition, and the Product Mix of Exporters," American Economic Review, 2014, 104 (2), 495-536.

Melitz, Marc, "Estimating Firm-level Productivity in Differentiated Product Industries," 2000. Unpub. paper, Harvard University.

Mondragón-Vélez, Camilo, Ximena Peña, and Daniel Wills, "Labor Market Rigidities and Informality in Colombia," Economía, 2010, 11 (1), 65-101.

Montiel Olea, José Luis and Carolin Pflueger, "A Robust Test for Weak Instruments," Journal of Business 85 Economic Statistics, 2013, 31 (3), 358-369.

Nerlove, Marc, "Returns to Scale in Electricity Supply," in Carl F. Christ, ed., Measurement in Economics: Studies in Mathematical Economics and Econometrics in Memory of Yehuda Grunfeld, Stanford University Press, 1963.

Olley, G. Steven and Ariel Pakes, "The Dynamics of Productivity in the Telecommunications Industry," Econometrica, 1996, 64 (6), 1263-1297.

Ornaghi, Carmine, "Assessing the Effects of Measurement Errors on the Estimation of Production Functions," Journal of Applied Econometrics, 2006, 21 (6), 879-891.

Orr, Scott, "Within-Firm Productivity Dispersion: Estimates and Implications," 2020. Unpub. paper.

Park, Albert, Dean Yang, Xinzheng Shi, and Yuan Jiang, "Exporting and Firm Performance: 
Chinese Exporters and the Asian Financial Crisis," Review of Economics and Statistics, 2010, 92 (4), 822-842.

Peter, Alessandra and Cian Ruane, "The Aggregate Importance of Intermediate Input Substitutability," 2020. Unpub. paper.

Redding, Stephen J. and David E. Weinstein, "Measuring Aggregate Price Indices with Taste Shocks: Theory and Evidence for CES Preferences," Quarterly Journal of Economics, 2020, 135 (1), 503-560.

Roberts, Mark J. and Dylan Supina, "Output Price, Markups, and Producer Size," European Economic Review, 04 1996, 40 (3-5), 909-921.

Roodman, David, "How To Do xtabond2: An Introduction to Difference and System GMM in Stata," Stata Journal, 2009, 9 (1), 86-136.

Rovigatti, Gabriele and Vincenzo Mollisi, "Theory and Practice of Total Factor Productivity Estimation: The Control Function Approach Using Stata," The Stata Journal, 2018, 18 (3), 618-662.

Rubens, Michael, "Market Structure, Oligopsony Power, and Productivity," 2020. Unpub. paper.

Sanderson, Eleanor and Frank Windmeijer, "A Weak Instrument F-test in Linear IV models with Multiple Endogenous Variables," Journal of Econometrics, 2016, 190 (2), 212-221.

Sato, Kazuo, "The Ideal Log-Change Index Number," Review of Economics and Statistics, 1976, 58, 223-228.

Shenoy, Ajay, "Estimating the Production Function when Firms are Constrained," Review of Economics and Statistics, forthcoming.

Smeets, Valerie and Frederic Warzynski, "Estimating Productivity with Multi-product Firms, Pricing Heterogeneity and the Role of International Trade," Journal of International Economics, 2013, 90 (2), $237-244$.

Söderbom, Måns and Francis Teal, "Size and Efficiency in African Manufacturing Firms: Evidence from Firm-Level Panel Data," Journal of Development Economics, 2004, 73 (1), 369-394.

Stewart, Mark B., "Estimating the Impact of the Minimum Wage Using Geographical Wage Variation," Oxford Bulletin of Economics and Statistics, 2002, 64 (supplement), 583-605.

Stock, James H. and Jonathan H. Wright, "GMM with Weak Identification," Econometrica, 2000, 68 (5), 1055-1096.

_ and Motohiro Yogo, "Testing for Weak Instruments in Linear IV Regression," in "Identification and Inference for Econometric Models: A Festschrift in Honor of Thomas J. Rothenberg," Cambridge UK: Cambridge University Press, 2005.

Stock, James H, Jonathan H Wright, and Motohiro Yogo, "A Survey of Weak Instruments and Weak Identification in Generalized Method of Moments," Journal of Business and Economic Statistics, 2002, 20 (4), 518-529.

Sun, Liyang, "Implementing Valid Two-Step Identification-Robust Confidence Sets for Linear Instrumental-Variables Models," The Stata Journal, 2018, 18 (4), 803-825.

Syverson, Chad, "What Determines Productivity?," Journal of Economic Literature, 2011, 49 (2), 32665.

Valmari, Nelli, "Estimating Production Functions of Multiproduct Firms," 2016. ETLA Working Papers no. 37 .

Van Biesebroeck, Johannes, "The Sensitivity of Productivity Estimates: Revisiting Three Important Debates," Journal of Business and Economic Statistics, 2008, 26 (3), 311 - 328.

Vartia, Yrjo, "Ideal Log-Change Index Numbers," Scandinavian Journal of Statistics, 1976, 3, 121-126.

Verhoogen, Eric, "Firm-Level Upgrading in Developing Countries," 2020. CDEP-CGEG working paper no. 83 , Columbia University.

Windmeijer, Frank, "A finite sample correction for the variance of linear efficient two-step GMM estimators," Journal of Econometrics, 2005, 126 (1), 25 - 51.

Wooldridge, Jeffrey M., "On Estimating Firm-Level Production Functions Using Proxy Variables to Control for Unobservables," Economics Letters, September 2009, 104 (3), 112-114.

_, Econometric Analysis of Cross Section and Panel Data, Cambridge, MA: MIT Press, 2010. 2nd edition. 
Table 1. Primary Outputs, Rubber and Plastic Products Producers

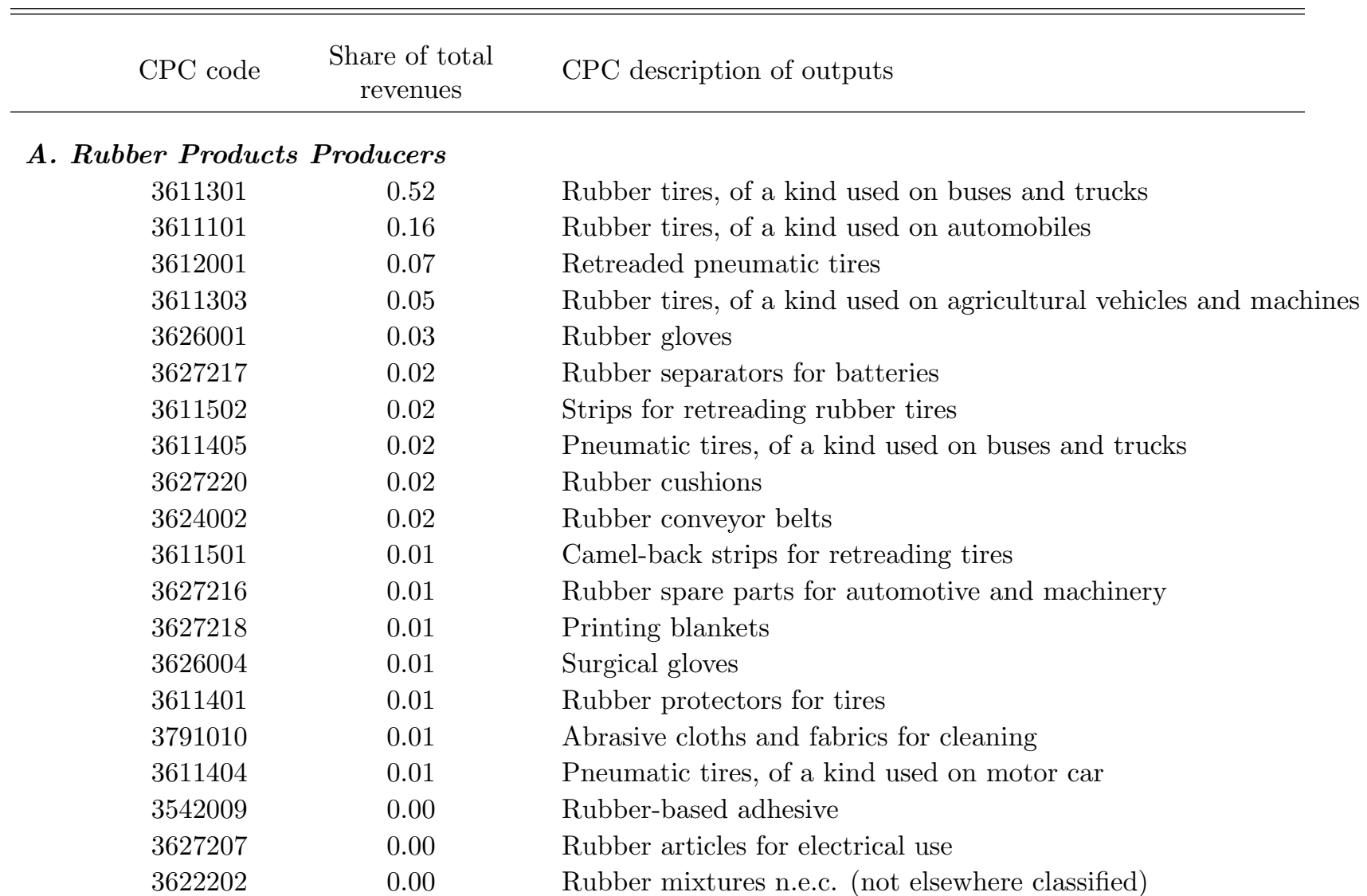

B. Plastic Products Producers

$\begin{array}{lll}3632001 & 0.09 & \text { Polyvinyl tubing } \\ 3641006 & 0.08 & \text { Printed plastic bags } \\ 3641003 & 0.08 & \text { Printed plastic film in tubular form } \\ 3633011 & 0.07 & \text { Polypropylene film } \\ 3633004 & 0.07 & \text { Polyethylene film } \\ 3641004 & 0.06 & \text { Unprinted plastic bags } \\ 3649007 & 0.06 & \text { Plastic caps and lids } \\ 3633012 & 0.05 & \text { Plastic laminated film } \\ 3649014 & 0.05 & \text { Blister packaging for medicines } \\ 3649002 & 0.05 & \text { Plastic containers of a capacity not exceeding } 1000 \mathrm{~cm} 3 \\ 3649003 & 0.05 & \text { Plastic containers of a capacity exceeding } 1000 \mathrm{~cm} 3 \\ 3633014 & 0.04 & \text { Printed polyethylene film } \\ 3694013 & 0.04 & \text { Plastic straws } \\ 3633008 & 0.04 & \text { Acrylic sheets } \\ 3641005 & 0.04 & \text { Synthetic sacks } \\ 3632008 & 0.03 & \text { Fabrics of polypropylen in tubular form } \\ 3649008 & 0.03 & \text { Plastic container for drugs and medicines } \\ 3633007 & 0.02 & \text { Polyvinyl film } \\ 3639201 & 0.02 & \text { Polyvinyl film with textile material } \\ 4153504 & 0.02 & \text { Laminated aluminum foil }\end{array}$

Notes: Baseline sample, producers of rubber and plastic products (ISIC rev. 2 categories 355 and 356), 1996-2009. Shares for each industry calculated as revenues from output over total revenues for 2000-2009 period, pooling firms and years. 
Table 2. Primary Inputs, Rubber and Plastic Products Producers

\begin{tabular}{|c|c|c|}
\hline CPC code & $\begin{array}{l}\text { Share of total } \\
\text { expenditures }\end{array}$ & CPC description of inputs \\
\hline \multicolumn{3}{|c|}{ A. Rubber Products Producers } \\
\hline 0321001 & 0.40 & Natural latex \\
\hline 3423112 & 0.12 & Carbon blacks and other forms of carbon \\
\hline 2799601 & 0.07 & Tire cord fabric \\
\hline 2819004 & 0.05 & Fabric of synthetic fiber in tubular form \\
\hline 3611502 & 0.05 & Strips for retreading rubber tires \\
\hline 4126301 & 0.04 & Iron or steel cable \\
\hline 3478007 & 0.04 & Nylon \\
\hline 3549405 & 0.03 & Stabilizers for synthetic resins \\
\hline 0321002 & 0.03 & Natural rubber in primary forms or in plates, sheets or strips \\
\hline 3633021 & 0.03 & Polypropylene fabric \\
\hline 3549934 & 0.03 & Food emulsifier \\
\hline 3480301 & 0.02 & Synthetic latex \\
\hline 3622101 & 0.02 & Rubber sheets \\
\hline 3549403 & 0.02 & Vulcanization Accelerators \\
\hline 3543102 & 0.01 & Mineral oils \\
\hline 3422101 & 0.01 & Dioxide, zinc oxide \\
\hline 3549401 & 0.01 & Plasticizers \\
\hline 3611402 & 0.01 & White strips for tires \\
\hline 3474002 & 0.01 & Polyester resins \\
\hline 3926001 & 0.01 & Used tires \\
\hline \multicolumn{3}{|c|}{ B. Plastic Products Producers } \\
\hline 3471001 & 0.35 & Polyethylene \\
\hline 3476001 & 0.14 & Polypropylene \\
\hline 3473002 & 0.12 & Polyvinyl chloride \\
\hline 3472001 & 0.05 & Polystyrene \\
\hline 3479902 & 0.04 & Synthetic emulsions \\
\hline 3474002 & 0.04 & Polyester resins \\
\hline 3549404 & 0.03 & Plastics additive \\
\hline 3513004 & 0.03 & Alcohol-based flexographic inks \\
\hline 3633011 & 0.03 & Polypropylene film \\
\hline 3434007 & 0.03 & Colorants for plastics \\
\hline 3415901 & 0.02 & Diisocyanates - desmophens - desmodurs \\
\hline 3411403 & 0.02 & Styrene \\
\hline 3215302 & 0.02 & Corrugated cardboard boxes \\
\hline 3633004 & 0.02 & Polyethylene film \\
\hline 3477002 & 0.02 & Acrylic resins \\
\hline 3479903 & 0.02 & Homopolymers \\
\hline 3474007 & 0.01 & Polyacetal thermoplastic resin \\
\hline 3549401 & 0.01 & Plasticizers \\
\hline 3413307 & 0.01 & Polyols \\
\hline 4153501 & 0.01 & Aluminum foil \\
\hline
\end{tabular}

Notes: Baseline sample, producers of rubber and plastics products. Shares for each industry calculated as expenditures on input over total expenditures for 2000-2009 period, pooling firms and years. 
Table 3. Summary Statistics

Rubber Plastics All

A. Period: 1996-2009

Number of Observations

$\begin{array}{ccc}554 & 3693 & 4247 \\ 46 & 316 & 362 \\ 98.08 & 101.37 & 100.94 \\ 10.46 & 8.83 & 9.04 \\ 7.14 & 7.00 & 7.02\end{array}$

Number of Firms

$7.14-7.00-7.02$

B. Period: 2000-2009

Input variables

No. inputs per firm in average firm-year

$\begin{array}{lll}11.66 & 8.01 \quad 8.46\end{array}$

Share of firms that import

$\begin{array}{lll}0.61 & 0.59 & 0.60\end{array}$

No. inputs per firm in avg. firm-year, cond. on importing

$\begin{array}{lll}16.57 & 10.34 & 11.18\end{array}$

Fraction of expenditure on imported inputs

$\begin{array}{lll}0.23 & 0.18 & 0.19\end{array}$

No. imported HS8 categories in avg. firm-year, cond. on importing

$29.55 \quad 19.41$

20.47

Output variables

No. outputs per firm in average firm-year

$3.54 \quad 3.08$

3.13

Share of firms that export

$0.48 \quad 0.55$

0.54

No. outputs per firm in avg. firm-year, cond. on exporting

$\begin{array}{lll}5.26 & 3.83 & 4.00\end{array}$

Fraction of revenues from exported outputs

$0.08 \quad 0.06 \quad 0.06$

No. exported HS8 categories in avg. firm-year, cond. on exporting $\quad \begin{array}{llll}5.64 & 5.38 & 5.41\end{array}$

Notes: Baseline sample, rubber and plastics products producers, 1996-2009. Table reports averages of firm-level values (giving every firm equal weight). Exports and imports available in EAM data only in 2000-2009. Average 2000 exchange rate is approximately 2,000 pesos/USD. 
Table 4. OLS and First Differences

(1)

(2)

(3)

(4)

\section{A. Sales and Expenditures}

\begin{tabular}{ccccc}
\multicolumn{2}{c}{$\log$ sales $_{i t}$} & & \multicolumn{2}{c}{$\triangle \log$ sales $_{i t}$} \\
\cline { 1 - 2 } $0.675^{* * *}$ & $0.675^{* * *}$ & & \\
$(0.027)$ & $(0.027)$ & & \\
$0.298^{* * *}$ & $0.296^{* * *}$ & & \\
$(0.039)$ & $(0.040)$ & & \\
$0.087^{* * *}$ & $0.087^{* * *}$ & & \\
$(0.019)$ & $(0.019)$ & & \\
& & $0.488^{* * *}$ & $0.485^{* * *}$ \\
& & $(0.050)$ & $(0.052)$ \\
& & $0.294^{* * *}$ & $0.288^{* * *}$ \\
& & $(0.037)$ & $(0.036)$ \\
$\mathrm{N}$ & $\mathrm{Y}$ & 0.010 & 0.010 \\
0.926 & 0.927 & $0.019)$ & $(0.018)$ \\
& & $\mathrm{N}$ & $\mathrm{Y}$ \\
& & 0.335 & 0.339
\end{tabular}

\section{B. Sato-Vartia Output and Input Indexes}

$\underline{\log \text { output index }\left(\widetilde{y}_{i t}^{S V}\right) \triangle \log \text { output index }\left(\triangle \widetilde{y}_{i t}^{S V}\right)}$

$\log$ materials index $\left(\widetilde{m}_{i t}^{S V}\right)$

$0.469^{* * *} \quad 0.468^{* * *}$

$\log$ labor $\left(\ell_{i t}\right)$

$(0.084) \quad(0.085)$

$0.357^{* * *} \quad 0.358 * * *$

$(0.109) \quad(0.110)$

$\log$ capital $\left(k_{i t}\right)$

$0.196 * * * \quad 0.195 * * *$

(0.045) (0.046)

$\triangle \log$ materials index $\left(\triangle \widetilde{m}_{i t}^{S V}\right)$

$\triangle \log$ labor $\left(\triangle \ell_{i t}\right)$

$0.434^{* * *} \quad 0.428^{* * *}$

(0.052)

$(0.053)$

$0.283^{* * *}$

$0.274^{* * *}$

(0.046)

(0.045)

$\triangle \log$ capital $\left(\triangle k_{i t}\right)$

$0.013 \quad 0.015$

(0.020)

(0.020)

Year effects

$\begin{array}{cc}\mathrm{N} & \mathrm{Y} \\ 0.704 & 0.705\end{array}$

$\mathrm{N}$

$\mathrm{Y}$

R-squared

0.704

0.258

0.263

Notes: Baseline sample: $\mathrm{N}$ (observations) $=4,247, \mathrm{~N}$ (distinct firms) $=362$ for all regressions. Dependent variables at top of columns. $\triangle$ refers to within-firm difference between $t-1$ and $t$. Robust standard errors in parentheses. $* 10 \%$ level, $* * 5 \%$ level, $* * * 1 \%$ level. 
Table 5. Differences (Step 1): First Stage

\begin{tabular}{|c|c|c|c|c|c|c|c|c|c|}
\hline & $\begin{array}{c}\triangle \widetilde{m}_{i t}^{S V} \\
\quad(1)\end{array}$ & $\begin{array}{c}\triangle \ell_{i t} \\
(2)\end{array}$ & $\begin{array}{c}\triangle k_{i t} \\
(3)\end{array}$ & $\begin{array}{c}\triangle \widetilde{m}_{i t}^{S V} \\
(4)\end{array}$ & $\begin{array}{c}\triangle \ell_{i t} \\
(5)\end{array}$ & $\begin{array}{c}\triangle k_{i t} \\
(6)\end{array}$ & $\begin{array}{c}\triangle \widetilde{m}_{i t}^{S V} \\
\quad(7)\end{array}$ & $\begin{array}{c}\triangle \ell_{i t} \\
(8)\end{array}$ & $\begin{array}{c}\triangle k_{i t} \\
(9)\end{array}$ \\
\hline$\tilde{m}_{i t-2}^{S V}$ & $\begin{array}{c}-0.017^{* * *} \\
(0.006)\end{array}$ & $\begin{array}{c}0.013^{* * *} \\
(0.004)\end{array}$ & $\begin{array}{c}0.027^{* * *} \\
(0.005)\end{array}$ & & & & $\begin{array}{c}-0.018^{* * *} \\
(0.006)\end{array}$ & $\begin{array}{c}0.013^{* * *} \\
(0.004)\end{array}$ & $\begin{array}{c}0.026^{* * *} \\
(0.005)\end{array}$ \\
\hline$\ell_{i t-2}$ & $\begin{array}{c}0.014 \\
(0.009)\end{array}$ & $\begin{array}{c}-0.030^{* * *} \\
(0.007)\end{array}$ & $\begin{array}{c}0.044^{* * *} \\
(0.010)\end{array}$ & & & & $\begin{array}{c}0.012 \\
(0.009)\end{array}$ & $\begin{array}{c}-0.031^{* * *} \\
(0.007)\end{array}$ & $\begin{array}{c}0.042^{\text {*** }} \\
(0.010)\end{array}$ \\
\hline$k_{i t-2}$ & $\begin{array}{c}0.009 \\
(0.006)\end{array}$ & $\begin{array}{c}0.009^{* *} \\
(0.004)\end{array}$ & $\begin{array}{c}-0.048^{* * *} \\
(0.007)\end{array}$ & $\begin{array}{c}0.001 \\
(0.002)\end{array}$ & $\begin{array}{c}0.002 \\
(0.002)\end{array}$ & $\begin{array}{c}-0.010^{* * *} \\
(0.003)\end{array}$ & $\begin{array}{c}0.007 \\
(0.006)\end{array}$ & $\begin{array}{c}0.008^{* *} \\
(0.004)\end{array}$ & $\begin{array}{c}-0.049^{* * *} \\
(0.007)\end{array}$ \\
\hline$\triangle$ pred. import price index $\left(\triangle \widehat{\widetilde{\widetilde{w}}}_{i t}^{i m p}\right)$ & & & & $\begin{array}{c}-0.245^{* *} \\
(0.097)\end{array}$ & $\begin{array}{l}-0.040 \\
(0.064)\end{array}$ & $\begin{array}{c}0.073 \\
(0.103)\end{array}$ & $\begin{array}{c}-0.254^{* * *} \\
(0.098)\end{array}$ & $\begin{array}{l}-0.047 \\
(0.063)\end{array}$ & $\begin{array}{c}0.119 \\
(0.102)\end{array}$ \\
\hline$\triangle \log$ min. wage x "bite" $\left(\triangle z_{i t}\right)$ & & & & $\begin{array}{c}-1.722^{* *} \\
-0.848\end{array}$ & $\begin{array}{c}-1.642^{* * *} \\
(0.489)\end{array}$ & $\begin{array}{c}-2.518^{* * *} \\
(0.605)\end{array}$ & $\begin{array}{c}-1.792^{* *} \\
(0.861)\end{array}$ & $\begin{array}{c}-1.734^{* * *} \\
(0.495)\end{array}$ & $\begin{array}{c}-2.028^{* * *} \\
(0.600)\end{array}$ \\
\hline Year effects & $\mathrm{Y}$ & $\mathrm{Y}$ & Y & $\mathrm{Y}$ & Y & $\mathrm{Y}$ & Y & $\mathrm{Y}$ & $\mathrm{Y}$ \\
\hline $\mathrm{N}$ & 4,247 & 4,247 & 4,247 & 4,247 & 4,247 & 4,247 & 4,247 & 4,247 & 4,247 \\
\hline R-squared & 0.024 & 0.035 & 0.038 & 0.025 & 0.031 & 0.015 & 0.026 & 0.039 & 0.041 \\
\hline F - statistic & 3.424 & 7.703 & 21.018 & 4.486 & 5.891 & 6.819 & 3.704 & 7.245 & 13.904 \\
\hline $\mathrm{F}-\mathrm{SW}$ & 2.070 & 2.366 & 2.258 & 4.179 & 4.988 & 17.373 & 5.897 & 12.195 & 17.354 \\
\hline KP LM test (underidentification) & & 1.995 & & & 3.925 & & & 15.88 & \\
\hline KP Wald F-test (weak insts.) & & 0.673 & & & 1.353 & & & 3.363 & \\
\hline
\end{tabular}

Notes: Dependent variables at tops of columns. SW refers to Sanderson and Windmeijer (2016), KP to Kleibergen and Paap (2006). The F-statistic is the standard $\mathrm{F}$ for a test that the coefficients on the excluded instruments (indicated at left) are zero. The KP statistics, LM test for under-identification and Wald $\mathrm{F}$ test for weak instruments, are for each IV model as a whole, and are not specific to Columns $2,5,8$. Robust standard errors in parentheses. $* 10 \%$ level, $* * 5 \%$ level, $* * * 1 \%$ level. 


\begin{tabular}{|c|c|c|c|c|}
\hline & \multicolumn{4}{|c|}{ Dep.var.: $\triangle \log$ output index $\left(\triangle \widetilde{y}_{i t}^{S V}\right)$} \\
\hline & $\begin{array}{c}\text { internal } \\
\text { instruments } \\
\text { only } \\
\text { (1) }\end{array}$ & $\begin{array}{c}\text { external } \\
\text { instruments } \\
+k_{i t-2} \\
(2)\end{array}$ & $\begin{array}{c}\text { internal \& } \\
\text { external } \\
\text { instruments } \\
\text { (3) }\end{array}$ & $\begin{array}{c}\text { internal \& } \\
\text { external } \\
\text { instruments } \\
\text { (LIML) } \\
(4)\end{array}$ \\
\hline$\triangle \log$ materials index $\left(\triangle \widetilde{m}_{i t}^{S V}\right)$ & $\begin{array}{c}0.520 \\
(0.487)\end{array}$ & $\begin{array}{c}0.247 \\
(0.541)\end{array}$ & $\begin{array}{c}0.381^{* *} \\
(0.177)\end{array}$ & $\begin{array}{c}0.381^{* *} \\
(0.179)\end{array}$ \\
\hline$\triangle \log$ labor $\left(\triangle \ell_{i t}\right)$ & $\begin{array}{c}0.485 \\
(0.394)\end{array}$ & $\begin{array}{c}0.600 \\
(0.714)\end{array}$ & $\begin{array}{c}0.397^{* *} \\
(0.184)\end{array}$ & $\begin{array}{c}0.397^{* *} \\
(0.184)\end{array}$ \\
\hline$\triangle \log$ capital $\left(\triangle k_{i t}\right)$ & $\begin{array}{l}-0.148 \\
(0.196)\end{array}$ & $\begin{array}{l}-0.211 \\
(0.215)\end{array}$ & $\begin{array}{l}-0.181 \\
(0.124)\end{array}$ & $\begin{array}{l}-0.181 \\
(0.124)\end{array}$ \\
\hline Year effects & $\mathrm{Y}$ & $\mathrm{Y}$ & $\mathrm{Y}$ & $\mathrm{Y}$ \\
\hline $\mathrm{N}$ & 4,247 & 4,247 & 4,247 & 4,247 \\
\hline R-squared & 0.224 & 0.191 & 0.239 & 0.239 \\
\hline Materials Robust (LC) Conf. Int. 90\% & & & {$[0.150-0.612]$} & $0.103-0.658]$ \\
\hline Labor Robust (LC) Conf. Int. $90 \%$ & & & {$[0.159-0.636]$} & $0.105-0.690]$ \\
\hline Materials Robust CI (LC) Conf. Int. 95\% & & & {$[0.106-0.656]$} & $0.050-0.711]$ \\
\hline Labor Robust CI (LC) Conf. Int. 95\% & & & {$[0.113-0.681]$} & $0.049-0.746]$ \\
\hline Arellano-Bond $\mathrm{AR}(2)$ statistic & 0.323 & 0.285 & 0.339 & 0.339 \\
\hline Arellano-Bond p-value & 0.746 & 0.776 & 0.735 & 0.735 \\
\hline
\end{tabular}

Notes: Corresponding first-stage estimates are in Table 5: Column 1 here corresponds to Columns 1-3, Column 2 to Columns 4-6, Column 3 to Columns 7-9 of Table 5. Robust standard errors in parentheses. Weak-instrumentrobust confidence intervals are based on LC test of Andrews (2018), implemented by Stata twostepweakiv command. Arellano-Bond statistic and p-value test for serial correlation in residual, based on Arellano and Bond (1991). *10\% level, ${ }^{* *} 5 \%$ level, ${ }^{* * *} 1 \%$ level. 
Table 7. Levels (Step 2): First and Second Stages

\section{A. First stage}

Dep.var.: $\log$ capital $\left(k_{i t}\right)$

(1)

(2)

$\triangle k_{i t-1}$

$0.666^{* * *}$

(0.106)

$\triangle k_{i t-2}$

$0.676^{* * *}$

(0.112)

Year effects

$\mathrm{N}$

$\mathrm{Y}$

$\mathrm{Y}$

4,247

4,131

$\mathrm{R}$ squared

0.028

0.027

Kleibergen-Paap LM test (underidentification)

43.269

40.554

Kleibergen-Paap Wald F-test (weak insts.)

39.453

36.727

\section{B. Second stage}

Dep.var.: $\widetilde{y}_{i t}^{S V}-\widehat{\beta}_{m} \widetilde{m}_{i t}^{S V}-\widehat{\beta}_{\ell} \ell_{i t}$

$\log$ capital $k_{i t}$

0.196

0.289

$0.239^{* * *}$

$(0.088)$

(0.101)

[0.188]

[0.196]

Year effects

$\begin{array}{ccc}\text { Y } & \text { Y } & \text { Y } \\ 4,247 & 4,131 & 4,247 \\ 0.173 & 0.170 & 0.258 \\ \text { IV } & \text { IV } & \text { OLS }\end{array}$

$\mathrm{N}$

R-squared

Specification

IV

258

ב

Notes: Panel B Columns 1-2 correspond to Panel A Columns 1-2. Panel C Column 3 is OLS.

Uncorrected robust standard errors in parentheses. Corrected robust standard errors in brackets. See Section 2.4.2 for details. *10\% level, **5\% level, ***1\% level. 


\begin{tabular}{|c|c|c|c|}
\hline & $(1)$ & $\begin{array}{c}\log \text { sales }_{i t} \\
(2)\end{array}$ & $(3)$ \\
\hline $\log$ sales $_{i t-1}$ & $\begin{array}{c}0.636^{* * *} \\
(0.079)\end{array}$ & $\begin{array}{c}0.607^{* * *} \\
(0.082)\end{array}$ & $\begin{array}{c}0.550 * * * \\
(0.082)\end{array}$ \\
\hline $\log$ expenditure $_{i t}$ & $\begin{array}{c}0.524^{* * *} \\
(0.083)\end{array}$ & $\begin{array}{c}0.537^{* * *} \\
(0.080)\end{array}$ & $\begin{array}{c}0.483^{* * *} \\
(0.059)\end{array}$ \\
\hline $\log$ expenditure $_{i t-1}$ & $\begin{array}{c}-0.250^{* * *} \\
(0.064)\end{array}$ & $\begin{array}{c}-0.232^{* * *} \\
(0.056)\end{array}$ & $\begin{array}{c}-0.179 * * * \\
(0.042)\end{array}$ \\
\hline $\log$ labor $\left(\ell_{i t}\right)$ & $\begin{array}{c}0.055 \\
(0.122)\end{array}$ & $\begin{array}{c}0.051 \\
(0.084)\end{array}$ & $\begin{array}{c}0.258 * * * \\
(0.067)\end{array}$ \\
\hline $\log$ labor $\left(\ell_{i t-1}\right)$ & $\begin{array}{c}0.068 \\
(0.112)\end{array}$ & $\begin{array}{c}0.062 \\
(0.084)\end{array}$ & $\begin{array}{l}-0.070 \\
(0.064)\end{array}$ \\
\hline $\log$ capital $\left(k_{i t}\right)$ & $\begin{array}{c}0.103^{*} \\
(0.062)\end{array}$ & $\begin{array}{c}0.050 \\
(0.062)\end{array}$ & $\begin{array}{c}0.033 \\
(0.040)\end{array}$ \\
\hline $\log$ capital $\left(k_{i t-1}\right)$ & $\begin{array}{c}-0.089^{*} \\
(0.050)\end{array}$ & $\begin{array}{l}-0.037 \\
(0.053)\end{array}$ & $\begin{array}{l}-0.014 \\
(0.034)\end{array}$ \\
\hline $\mathrm{N}$ & 4,247 & 4,247 & 4,247 \\
\hline Lag limit & 2 & 3 & all \\
\hline Hansen test & 107.0 & 156.4 & 344.2 \\
\hline Hansen p-value & 0.428 & 0.587 & 1.000 \\
\hline
\end{tabular}

Notes: Table presents estimates of standard System GMM model (Blundell and Bond, 2000), using the "two-step" procedure described in Roodman (2009), with initial weighting matrix defined in Doornik et al. (2012) and finite-sample correction from Windmeijer (2005). The Stata command is xtabond2 (Roodman, 2009), with options $\mathrm{h}(2)$, twostep, and robust. The difference equation includes lags to $t-2$ in Column 1 , lags to $t-3$ in Column 2, and all available lags in Column 3. The numbers of instruments are as indicated in Appendix Table A12. The Hansen test of overidentifying restrictions is appropriate in the non-homoskedastic case, but should be interpreted with caution, as it is weakened by the presence of many instruments. See Section 6 for further details. Robust standard errors in parentheses. ${ }^{*} 10 \%$ level, $* * 5 \%$ level, $* * * 1 \%$ level. 
Table 9. Proxy-Variable Methods

\begin{tabular}{|c|c|c|c|c|}
\hline & \multicolumn{4}{|c|}{${\text { Dep.var.: } \log \text { sales }_{i t}}$} \\
\hline & $\begin{array}{l}\mathrm{OP} \\
(1)\end{array}$ & $\begin{array}{l}\mathrm{LP} \\
(2)\end{array}$ & $\begin{array}{c}\text { Wooldridge } \\
\text { (3) }\end{array}$ & $\begin{array}{l}\text { GNR } \\
(4)\end{array}$ \\
\hline $\log$ expenditure $_{i t}$ & $\begin{array}{c}0.672^{* * *} \\
(0.028)\end{array}$ & $\begin{array}{c}0.636^{* * *} \\
(0.033)\end{array}$ & $\begin{array}{c}0.604^{* * *} \\
(0.019)\end{array}$ & $\begin{array}{c}0.406^{\text {*** }} \\
(0.010)\end{array}$ \\
\hline $\log$ labor $\left(\ell_{i t}\right)$ & $\begin{array}{c}0.258^{* * *} \\
(0.049)\end{array}$ & $\begin{array}{c}0.289^{* * *} \\
(0.046)\end{array}$ & $\begin{array}{c}0.290 * * * \\
(0.010)\end{array}$ & $\begin{array}{c}0.513^{* * *} \\
(0.035)\end{array}$ \\
\hline $\log$ capital $\left(k_{i t}\right)$ & $\begin{array}{c}0.131^{* * *} \\
(0.035)\end{array}$ & $\begin{array}{c}0.113^{* * *} \\
(0.035)\end{array}$ & $\begin{array}{c}0.054^{* *} \\
(0.025)\end{array}$ & $\begin{array}{c}0.138^{* * *} \\
(0.027)\end{array}$ \\
\hline $\mathrm{N}$ & 1,933 & 4,247 & 4,247 & 4,247 \\
\hline
\end{tabular}

Notes: Table presents estimates in our baseline sample from proxy-variable methods of Olley and Pakes (1996) (OP), Levinsohn and Petrin (2003) (LP), Wooldridge (2009) (using materials as the proxy), and Gandhi et al. (2020) (GNR). OP, LP, and Wooldridge estimates generated by Stata command prodest (Rovigatti and Mollisi, 2018). GNR estimates from authors' own code. See Section 6 for further details. Standard errors in parentheses from bootstraps with 50 replications. ${ }^{*} 10 \%$ level, **5\% level, ***1\% level. 
Table 10. $\triangle$ TFP (Standardized) as Predictor of Future Export Growth

\begin{tabular}{|c|c|c|c|}
\hline & \multicolumn{3}{|c|}{$\operatorname{asinh}\left(\operatorname{export}\right.$ value $\left._{i t+s}\right)-\operatorname{asinh}($ export value $i t)$} \\
\hline & $\begin{array}{c}s=1 \\
(1)\end{array}$ & $\begin{array}{c}s=2 \\
(2)\end{array}$ & $\begin{array}{c}s=3 \\
(3)\end{array}$ \\
\hline \multicolumn{4}{|l|}{ A. TSIV } \\
\hline$T F P_{t}^{T S I V}-T F P_{t-s}^{T S I V}$ & $\begin{array}{c}0.097 \\
(0.310)\end{array}$ & $\begin{array}{c}1.204^{* * *} \\
(0.321)\end{array}$ & $\begin{array}{c}1.633^{* * *} \\
(0.365)\end{array}$ \\
\hline R-squared & 0.005 & 0.012 & 0.017 \\
\hline $\begin{array}{l}\text { B. OLS using Sato-Vartia } \\
T F P_{t}^{O L S-S V}-T F P_{t-s}^{O L S-S V}\end{array}$ & $\begin{array}{c}\text { xes } \\
\quad 0.074 \\
(0.152)\end{array}$ & $\begin{array}{c}0.437^{* * *} \\
(0.156)\end{array}$ & $\begin{array}{c}0.463^{* *} \\
(0.181)\end{array}$ \\
\hline R-squared & 0.005 & 0.010 & 0.011 \\
\hline $\begin{array}{l}\text { C. System GMM } \\
T F P_{t}^{\text {Sys } G M M}-T F P_{t-s}^{\text {Sys } G M M}\end{array}$ & $\begin{array}{c}0.158 \\
(0.210)\end{array}$ & $\begin{array}{c}0.753^{* * *} \\
(0.219)\end{array}$ & $\begin{array}{c}0.971^{* * *} \\
(0.254)\end{array}$ \\
\hline R-squared & 0.005 & 0.012 & 0.015 \\
\hline \multicolumn{4}{|l|}{ D. Olley and Pakes } \\
\hline$T F P_{t}^{O P}-T F P_{t-s}^{O P}$ & $\begin{array}{c}0.071 \\
(0.138)\end{array}$ & $\begin{array}{c}0.329 * * \\
(0.145)\end{array}$ & $\begin{array}{c}0.411^{* *} \\
(0.170)\end{array}$ \\
\hline R-squared & 0.005 & 0.009 & 0.011 \\
\hline $\begin{array}{l}\text { E. Levinsohn and Petrin } \\
T F P_{t}^{L P}-T F P_{t-s}^{L P}\end{array}$ & $\begin{array}{c}0.071 \\
(0.139)\end{array}$ & $\begin{array}{c}0.350^{* *} \\
(0.146)\end{array}$ & $\begin{array}{c}0.427^{* *} \\
(0.171)\end{array}$ \\
\hline R-squared & 0.005 & 0.009 & 0.011 \\
\hline \multicolumn{4}{|l|}{ F. Wooldridge } \\
\hline$T F P_{t}^{W}-T F P_{t-s}^{W}$ & $\begin{array}{c}0.091 \\
(0.154)\end{array}$ & $\begin{array}{c}0.452^{* * *} \\
(0.162)\end{array}$ & $\begin{array}{c}0.577^{* * *} \\
(0.190)\end{array}$ \\
\hline R-squared & 0.005 & 0.010 & 0.012 \\
\hline $\begin{array}{l}\text { G. Gandhi, Navarro and } \boldsymbol{I} \\
T F P_{t}^{G N R}-T F P_{t-s}^{G N R}\end{array}$ & $\begin{array}{c}0.035 \\
(0.155)\end{array}$ & $\begin{array}{c}0.460^{* * *} \\
(0.159)\end{array}$ & $\begin{array}{c}0.463^{* *} \\
(0.185)\end{array}$ \\
\hline R-squared & 0.005 & 0.010 & 0.011 \\
\hline $\begin{array}{l}\text { H. Ackerberg, Caves and } \mathrm{I} \\
T F P_{t}^{A C F}-T F P_{t-s}^{A C F}\end{array}$ & $\begin{array}{c}0.149 \\
(0.126)\end{array}$ & $\begin{array}{l}0.343^{* *} \\
(0.135)\end{array}$ & $\begin{array}{c}0.353^{* *} \\
(0.152)\end{array}$ \\
\hline R-squared & 0.005 & 0.010 & 0.010 \\
\hline $\mathrm{N}$ & 3,539 & 2,835 & 2,127 \\
\hline Year effects & $\mathrm{Y}$ & $\mathrm{Y}$ & $\mathrm{Y}$ \\
\hline
\end{tabular}

Notes: TFP calculated in levels (see Appendix Table A14 for details and pairwise correlations), then standardized by year to have variance 1 (pooling years). (For OP method, TFP calculated for all observations in baseline sample, even those with zero investment omitted from estimation in Table 9.) Robust standard errors in parentheses. ${ }^{*} 10 \%$ level, ${ }^{* *} 5 \%$ level, ${ }^{* * *} 1 \%$ level. 